\title{
Determining silt state from CPTu
}

Dawn Shuttle PhD, MICE, PEng

Consulting Engineer, Surrey, BC, Canada (dawn_shuttle@hotmail.com)
Michael Jefferies PEng

Consulting Engineer, Surrey, BC, Canada (corresponding author: geomek@hotmail.com)

Tailings, produced when rock is crushed to recover metals, are normally discharged as slurry of predominantly siltsized particles into storage areas that are created using dams. These dams have a poor safety record with billions of dollars in damages over the past decade alone, making reliable engineering of silt an important economic and safety issue for the mining industry. Equally, engineering of silts is challenging, as understanding of soil behaviour relates mostly to 'sands' or 'clays'. Undisturbed silt samples suffer substantial densification between sampling, transfer to element test and reinstatement of in situ stresses. Hence, silts require a sand-like approach that combines laboratory tests on reconstituted samples with in situ cone penetration test (CPT) soundings. This paper presents calibrated spherical cavity expansion in a general critical-state soil model to simulate the CPT in silt. The developed methodology is numerical, accurately captures calibration data and allows determination of the in situ state parameter in silts from CPT data. A validation is presented for a large tailing impoundment using stacked thickened tailings. Open-source software implementing the methodology is provided on the journal website as supplementary material.

\section{Notation}

A

$B_{\mathrm{q}}$

$C_{c}$

$C_{Q}$

$C_{\mathrm{S}}$

$c_{1}, \ldots, c_{4}$

$c_{\mathrm{k}}, c_{\mathrm{m}}$

D

$D^{\mathrm{p}}$

e

F

G

$G_{\text {max }}$

$H$

$I_{\mathrm{r}}$

K

$K_{0}$

$k, m$

M

N

$N_{\mathrm{KT}}$

P

$p^{\prime}$

$Q, N_{\mathrm{q}}$

$Q_{\mathrm{p}}$

$Q_{\text {sph }}$

$q$ coefficient in elasticity model: $F / L^{2}$

dimensionless excess pore pressure $=\left(u_{2}-u_{0}\right) /\left(q_{\mathrm{t}}-p_{0}\right)$ compression index

scaling factor $=Q_{\mathrm{p}} / Q_{\mathrm{sph}}$

swelling index

coefficients in solution of spherical cavity expansion

contributory coefficients to $C_{Q}$

dilatancy, as strain rate ratio $\dot{\varepsilon}_{\mathrm{v}} / \dot{\varepsilon}_{\mathrm{q}}$

plastic dilatancy, as strain rate ratio $\dot{\varepsilon}_{\mathrm{v}}^{\mathrm{p}} / \dot{\varepsilon}_{\mathrm{q}}^{\mathrm{p}}$

void ratio

friction ratio

elastic shear modulus: $F / L^{2}$

elastic shear modulus measured geophysically: $F / L^{2}$

plastic hardening modulus

soil shear rigidity $\left(=G / \bar{\sigma}_{\mathrm{m}}\right)$

elastic bulk modulus: $F / L^{2}$

geostatic stress ratio prior to loading; $K_{0}=\bar{\sigma}_{h 0} / \bar{\sigma}_{\nu 0}$ dimensionless coefficients in $Q_{\mathrm{p}}=k \exp (-m \psi)$ critical friction ratio; equals $\eta_{\mathrm{c}}$ at the critical state;

varies with Lode angle, value at triaxial compression $\left(M_{\mathrm{tc}}\right)$ taken as the soil property

volumetric coupling parameter (from Nova's flow rule) undrained strength 'cone factor' relating $s_{\mathrm{u}}$ to $q_{\mathrm{t}}$ internal pressure of expanding cavity: $F / L^{2}$ mean effective stress $\left(=\bar{\sigma}_{\mathrm{m}}\right): F / L^{2}$

dimensionless tip resistance or bearing capacity factor; $N_{\mathrm{q}}=Q=\left(q_{\mathrm{t}}-\sigma_{\mathrm{v} 0}\right) / \sigma_{\mathrm{v} 0}^{\prime}$

dimensionless cone penetration test (CPT) tip resistance defined using mean stress $=\left(q_{\mathrm{t}}-p_{0}\right) / p_{0}^{\prime}$ dimensionless spherical cavity limit $=\left(P_{\text {lim }}-p_{0}\right) / p_{0}^{\prime}$ triaxial deviator stress; $q=\sigma_{1}-\sigma_{3}\left(=\bar{\sigma}_{\mathrm{q}}\right): F / L^{2}$ $q_{\mathrm{t}}$

$R$

$S_{\mathrm{u}}$ $u$

$V_{\mathrm{s}}$

$v$

$\delta$

$\Gamma$

$\varepsilon_{1}, \varepsilon_{2}, \varepsilon_{3}$

$\dot{\varepsilon}_{\mathrm{q}}$

$\dot{\varepsilon}_{\mathrm{v}}$

$\kappa$

$\lambda, \lambda_{10}$

$\eta$

$v$

$\rho$

$\sigma_{1}, \sigma_{2}, \sigma_{3}$

$\bar{\sigma}_{\mathrm{m}}$

$\bar{\sigma}_{\mathrm{q}}$

$\psi$

$\phi_{\mathrm{c}}$

$\chi$
CPT tip resistance: $F / L^{2}$

scalar measure of overconsolidation

undrained soil strength: $F / L^{2}$

pore pressure: $F / L^{2}$

shear wave velocity: $L / T$

specific volume $=1+e$

dilation angle (usually in NAMC model):

reference void ratio on critical-state locus,

conventionally defined at $p^{\prime}=1 \mathrm{kPa}$

principal strains (assumed coaxial with principal stresses)

shear strain rate measure work conjugate with $\bar{\sigma}_{\mathrm{q}}$; $\dot{\varepsilon}_{\mathrm{q}}=(1 / 3)\left[\left(\sin \theta+3^{1 / 2} \cos \theta\right) \dot{\varepsilon}_{1}-2 \sin \theta \dot{\varepsilon}_{2}+\right.$ $\left.\left(\sin \theta-3^{1 / 2} \cos \theta\right) \dot{\varepsilon}_{3}\right]$

volumetric strain rate; $\dot{\varepsilon}_{\mathrm{v}}=\dot{\varepsilon}_{1}+\dot{\varepsilon}_{2}+\dot{\varepsilon}_{3}$

slope of unload-reload line in $e-\ln \left(p^{\prime}\right)$ framework

slope of critical-state locus, for semi-log

idealisation; default is base e; subscript 10 denotes

base 10 logarithm $\left(\lambda_{10} \approx 2 \cdot 3 \lambda\right)$

dimensionless shear stress measured as ratio of

stress invariants; $\eta=\bar{\sigma}_{\mathrm{q}} / \bar{\sigma}_{\mathrm{m}}$

Lode angle: radians

Poisson's ratio

density (total): $M / L^{3}$

principal stresses: $F / L^{2}$

mean effective stress; $\bar{\sigma}_{\mathrm{m}}=\left(\bar{\sigma}_{1}+\bar{\sigma}_{2}+\bar{\sigma}_{3}\right) / 3: F / L^{2}$

deviatoric stress invariant; $\bar{\sigma}_{\mathrm{q}}=\left[(1 / 2)\left(\sigma_{1}-\sigma_{2}\right)^{2}+\right.$

$\left.(1 / 2)\left(\sigma_{2}-\sigma_{3}\right)^{2}+(1 / 2)\left(\sigma_{3}-\sigma_{1}\right)^{2}\right]^{1 / 2}: F / L^{2}$

state parameter; $\psi=e-e_{\mathrm{c}}$

critical-state friction angle:

state-dilatancy constant; value in triaxial

compression taken as the soil property 


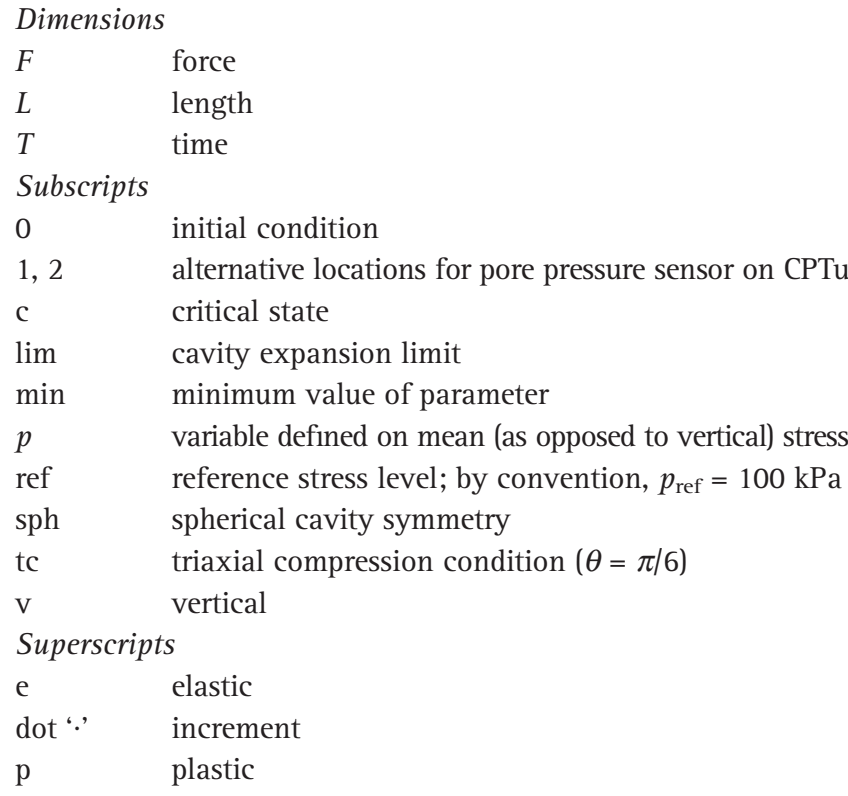

\section{Introduction}

Tailings are produced when rock is crushed to recover metals, and are predominantly silt. Figure 1 illustrates some examples of gradations. Tailings are discharged as slurry into natural valleys closed with dams or by complete perimeter containment dykes, generically known as tailing storage facilities (TSFs). Tailings within a TSF are commonly characterised using the cone penetration test (CPT), and some examples of CPT data are shown in Figure 2 to illustrate their in situ condition. The sand fraction drops out of the slurry, usually forming a beach near the spigot point, with these sands being slightly contractive. The silt fraction moves down the TSF and often accumulates under the reclaim pond, these silts being very weak (perhaps half the strength of a geologically idealised, normally consolidated recent clay, a possible consequence of the very young age of these silts). By way of comparison, Figure 1 also includes two natural silts: one from a deposit on Vancouver Island near John Hart dam, while the other is a natural silt that was sluiced from a borrow pit and then deposited as a slurry to form the core of Coquitlam dam (located near Vancouver City, British Columbia, Canada).

A new trend in mining has been to process the tailing slurry to reduce its water content ('thickened' or 'paste' tailings), which generally prevents hydraulic segregation during discharge and offers two advantages: a very substantial reduction in the potential for acid drainage in the long term (near eliminating potential environmental damage from this source) and a sufficient strength (see Figure 2) so that the thickened tailings can be stacked above the crest of the retaining dams/dykes (favourably affecting mine economics). In short, hydraulically placed silts are now being used as, in effect, structural fills within the TSF. Although these fills are at shallow slopes (say less than $6 \%$ vertical:horizontal $(\mathrm{V}: \mathrm{H})$ ), the scale of tailing impoundments is such that some current mine plans envisage stacked tailings more than $30 \mathrm{~m}$ above the crest of the original retaining dams/dykes. The situation is further complicated by the more valuable ore bodies seemingly always being found in earthquakeprone areas - liquefaction is a pervasive concern. And TSFs have

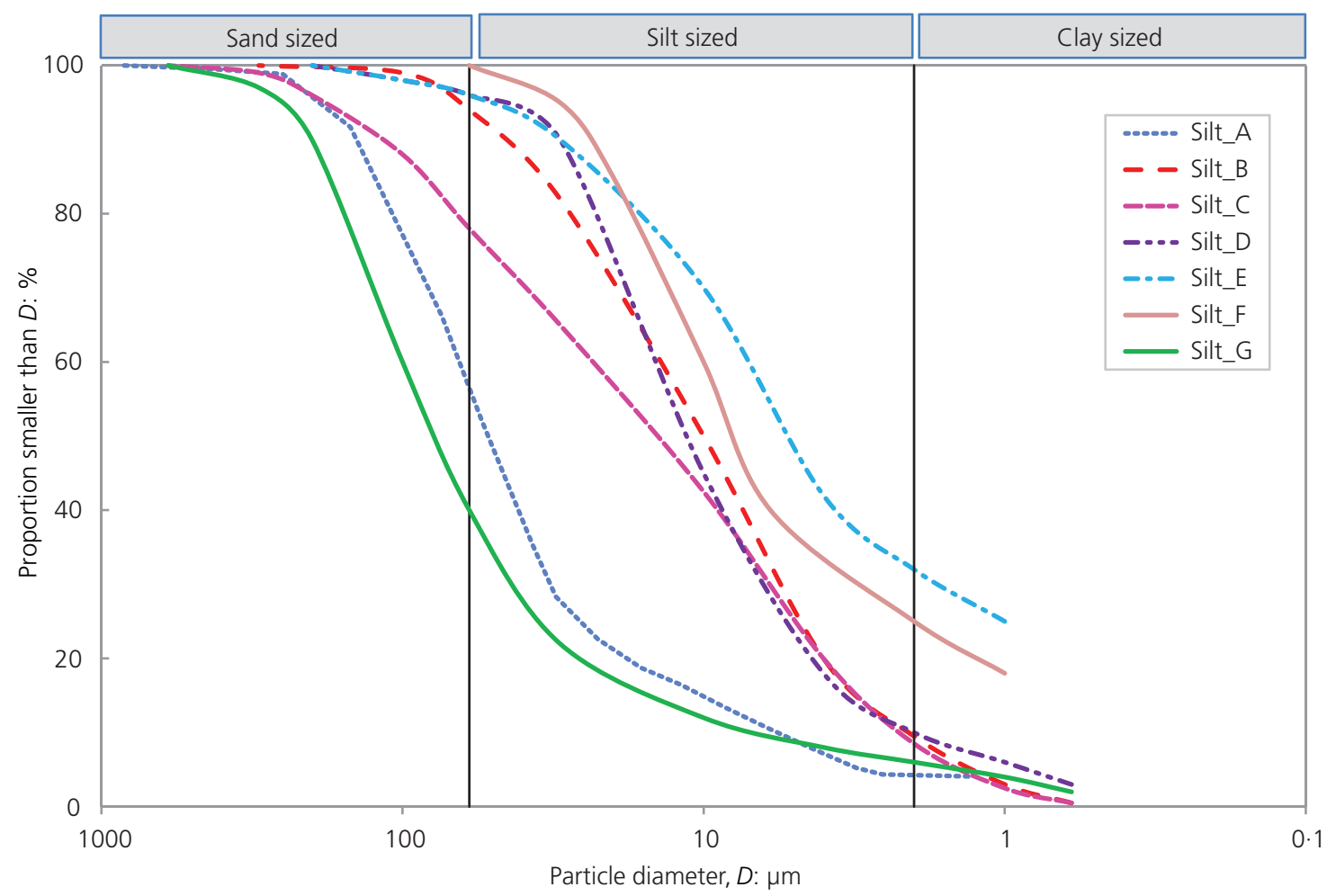

Figure 1. Tailing gradations illustrating dominance of silt fraction 


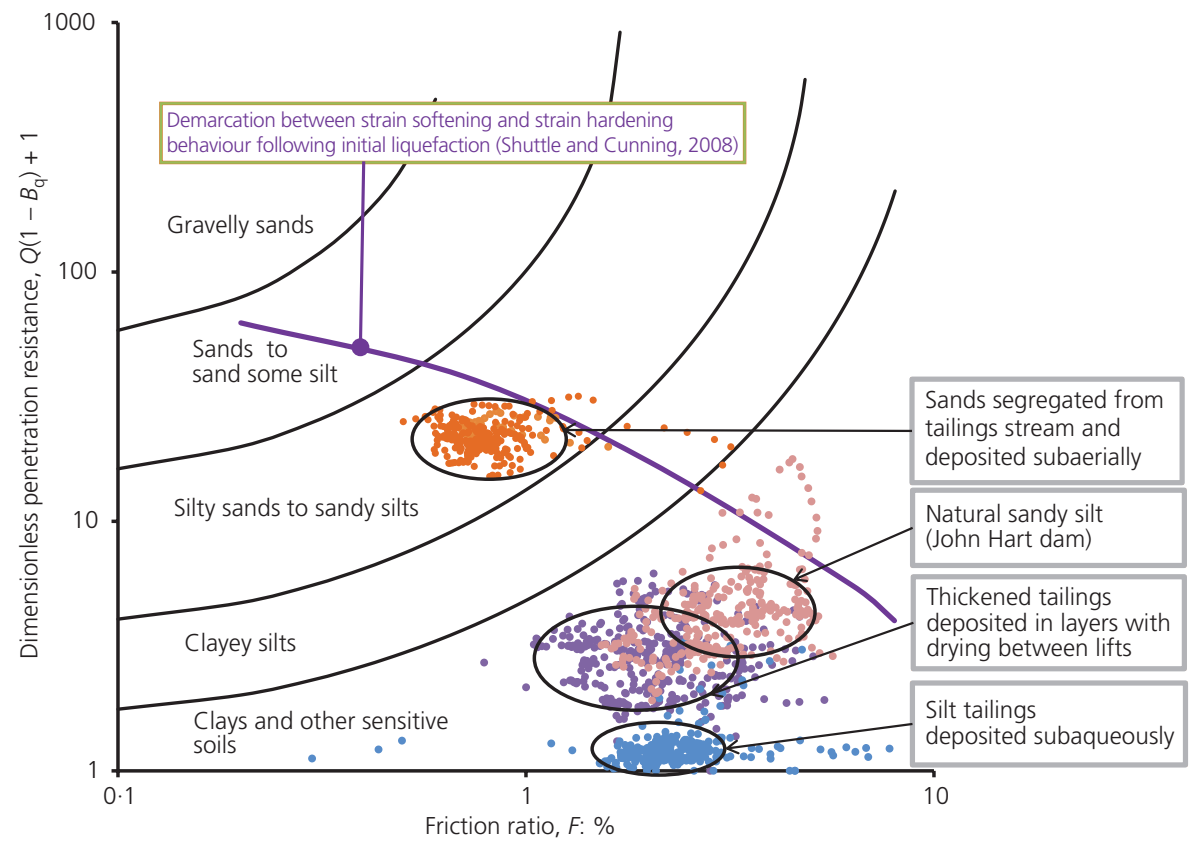

Figure 2. Examples of in situ states of tailings from piezocone penetration test (CPTu) data

less than a stellar safety record - for example, the Aberfan disaster of 1966 (UK, 144 dead: summarised in Wikipedia (2016a); also see Bishop (1973)), Los Frailes dam failure in 1988 (Spain, billions of dollars: Boliden (2016); also see Alonso and Gens (2006)), Mount Polley dam failure in 2014 (one of the largest environmental disaster in Canadian history: summarised in Wikipedia (2016b); also see Mount Polley Review Panel (2016)) and last year the complete failure of Fundão dam (Brazil, billions of dollars in damage with at least 17 deaths: summarised in Wikipedia (2016c); also see FTDRP (2016)). Reliable engineering of silt is an important economic and safety issue in the mining industry - and this issue is a challenge for geotechnical engineering, as nearly all the understanding of the mechanical behaviour of soil, as found in the literature, relates to either 'sands' or 'clays'. There are good reasons for this situation.

In the case of clay soils, undisturbed samples can be recovered and then transferred to an 'element' test (such as triaxial compression or simple shear) - there can be some discussion about the disturbance and how that disturbance can be dealt with, but there are existing protocols for measuring soil properties. This testing of undisturbed samples is easily extended to investigate the 'fundamental aspects' of clay behaviour, as clay samples can be remoulded, across a spectrum of water contents (void ratios), to investigate directly the effect of void ratio and stress history on clay behaviour. Further, clay soils are amenable to in situ tests that invoke few assumptions - vane shear is an example of this, where the measured torque is directly reduced to undrained shear strength by assuming that the vane sweeps a right cylindrical failure surface in the clay. In situ measurements are readily compared to laboratory measurements. A range of views exist in the literature on the relative merits of in situ testing against laboratory tests on undisturbed samples (with clear cultural bias - for example, UK practice and protocols are different from those in the USA), but, overall, there is a good basis for engineering clays in essentially any loading/situation.

In the case of sands, undisturbed samples of sand are essentially impossible - even samples cored into in situ frozen sand show gross densification when thawed and consolidated at in situ stress. In an effort to get better samples at less cost than freezing, the Japanese 'gel push' sampler has been used with silty sands (e.g. Taylor et al. (2012)) - but there remains a concerning issue of investigators not comparing the as-recovered void ratio (when the sampler first arrives at the surface) to the as-tested void ratio (after the sample is in the element test cell at the in situ stress level); there is an apparent belief that void ratio does not matter with silty sands, despite this easily being shown not to be the case when using reconstituted samples. Reliance on undisturbed samples also misses a key issue - general understanding cannot be gained from a single test. Rather, a series of tests on similar samples are required so that fundamental understanding of sand behaviour is based on preparing reconstituted samples in the laboratory and then testing those samples in element tests; protocols have been developed (e.g. moist tamping, air pluviation, wet pluviation), allowing repeatable samples to be prepared across a range of void ratios. However, sand behaviour (under all loading paths) depends on the state parameter, not void ratio itself, with small changes in gradation affecting the critical void ratio; simply measuring the void ratio forces the nearly impossible task of also measuring the critical state for the soil gradation with that void ratio (a process that must be repeated for every void ratio measured). Accordingly, in situ 
penetration tests (originally the standard penetration test; nowadays almost always the electronic $\mathrm{CPTu}$ ) are used to determine the in situ state of sands (some workers consider the pressuremeter and dilatometer as alternatives to the CPT). In situ penetration tests, however, measure a mechanical response, and there is no simple, accepted formula for converting the measured penetration resistance to state measures (state parameter, relative density) or related strength measures (peak friction angle, peak dilation angle). Rather, the use of penetration tests relies on calibration chamber studies in which a systematic set of controlled, large-scale laboratory tests has allowed development of mappings between void ratio, confining stress and penetration resistance. As there is no single mapping applicable to all sands, a basis is also needed to relate the particular circumstances being considered to the range of published mappings (it is rare to develop a site-specific mapping). Overall, while, arguably, engineering sands have a greater range of views over appropriate practice/protocols than exists in the case of clays, there is also a substantial knowledge base for engineering sands.

So, what is the situation with silt? Silt can be sampled without much more difficulty than clays; mud-rotary drilling with a thinwalled unswaged Shelby tube is often sufficient, although some silts may require a fixed-piston sampler, much as for soft clay. Silts have a sufficiently low hydraulic conductivity so that these samples can be extruded, trimmed and moved to element testing equipment (triaxial, oedometer or simple shear). However, there is densification between what is recovered to the surface in the sampler and the same soil after transfer to the element test and reinstatement of the in situ stress on the sample. The disturbance appears to arise, in part, because of plastic strains imposed on the sample as it is extruded and transferred to the test equipment; there is also the possibility that yield in unloading (see Jefferies (1997)), which is intrinsic to extruding the sample, induces plastic strains - and thus that disturbance may be intrinsic, for even ideal samplers, as it is a consequence of stress change.

The magnitude of this disturbance is illustrated for a loose natural clayey silt. Mohajeri and Ghafghazi (2012) reported on a comprehensive investigation in connection with the John Hart dam upgrading. The interest here is on the near normally consolidated low-plasticity silt $(10<\mathrm{PI}<18)$ in the depth range $26-35 \mathrm{~m}$ at the location known as Test Site 1. The gradation is Silt_G in Figure 1, and gradationally it is actually a sandy silt, despite being classified as a low-plasticity clay by Atterberg limits. Figure 2 shows the CPT data adjacent to the sampled zone on a soil behaviour-type plot, with the data indicating a sensitive clayey or silty soil that is distinctly contractive according to the Shuttle and Cunning (2008) criterion. The geology of this site is reasonably understood, with the horizon of interest deposited in a complex sedimentary sequence because of changing sea levels, isostatic rebound, waves, tides and other factors. The clays range between thinly laminated beds separated by very thin, fine sand seams to massive layers as much as $10 \mathrm{~m}$ thick. A fixed-piston sampler was used, with extremely gentle handling while transporting to the testing laboratory. Gamma ray imaging was used to identify any potential defects inside the tubes prior to sample extrusion, with careful selection and trimming of the soil tested. Yet, despite this level of care, rather large densification, averaging about $\Delta e \approx 0 \cdot 15$, was found between the as-recovered void ratio and the astested void ratio after the sample was in the test equipment and with the vertical effective stress reinstated (Figure 3). The soil, although classified as low-plasticity clay, exhibits a behaviour in response to disturbance that is much like what would be expected with sand. This behaviour is not so unusual for some Canadian clays (e.g. Becker et al. (2006)), as their silt and clay fractions are rock flours.

The importance of sample densification for this John Hart silt was investigated by reconstituting two samples at different water contents and then identically consolidating them before testing them in cyclic simple shear under identical loadings. The results are shown in Figure 4. Although the void ratio difference achieved between the two samples was only $\Delta e=0 \cdot 06$, even this difference doubled/halved the number of cycles to initial liquefaction. Patently, the void ratio shifts shown in Figure 3 will have a profound influence on the liquefaction resistance assessed for remedial engineering. Of course, the important question then becomes, how should this effect be assessed? And the effect is general in its consequences - for example, including the important post-liquefaction residual strength.

There are two alternative, and complementary, approaches to characterising silts: $(a)$ measuring strengths in the laboratory and correcting the results for the measured densification from 'as-recovered' (= in situ?) to 'as-tested' conditions and/or (b) treating silts as sand-like, measuring the state parameter $\psi$ onsite and using that state to compute in situ strengths from measured soil properties by using reconstituted samples. This paper primarily addresses approach $(b)$, with some contribution from approach $(a)$ to provide validation. An effective stress approach is followed, looking to use both the CPT resistance and the induced excess pore pressure. A further consideration as to why the approach should be anchored to the CPT is that the

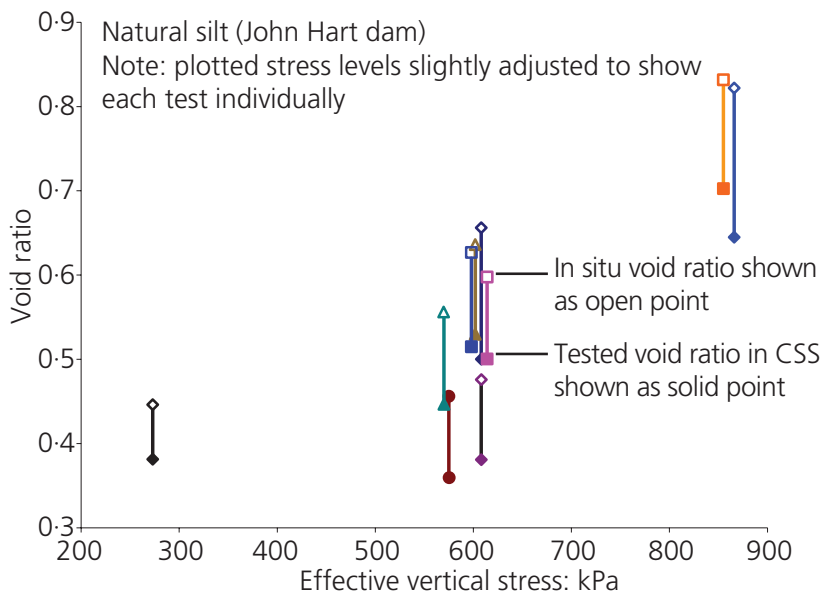

Figure 3. Measured silt densification from in situ to as-tested condition 


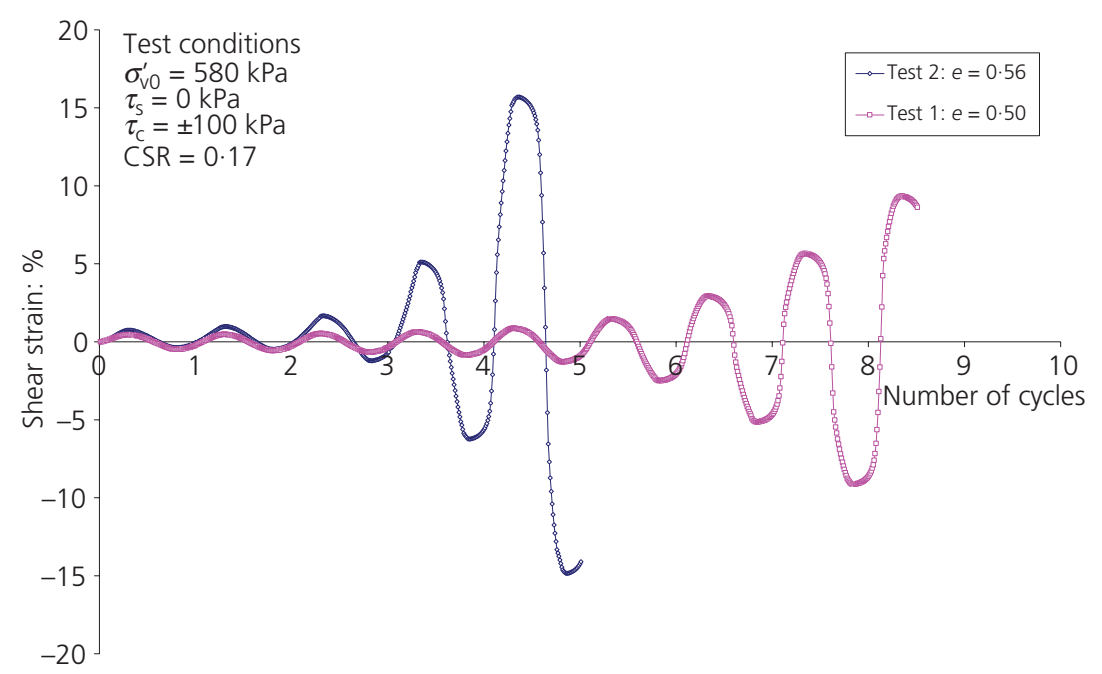

Figure 4. Effect of small void ratio change on remoulded silt in cyclic simple shear

standard of practice for liquefaction assessments (e.g. Youd et al. (2001)) presently mandates penetration tests.

\section{Silt behaviour}

Silts are fine-grained soils whose behaviour is controlled by forces transmitted through contacts between the particles - in essence, the same as sands but with much smaller hydraulic conductivity because of the much smaller distances between particles. The physical and mathematical representation of particulate soils behaviour is gelling into the common understanding with, since about 1990, the universal acknowledgement that soils exhibit a critical void ratio that depends on the stress level (the critical-state locus (CSL)); stress dilatancy links the ratio of strain increments to stress; dilatancy scales with the void ratio offset from the CSL (the state parameter $\psi$ ); and soils are work-hardening/work-softening plastic materials within the framework of theoretical plasticity. Silts fit this common understanding, as will now be illustrated.

\section{Critical-state locus}

Silts display well-defined CSLs. Figure 5 shows two examples (Silt_B and Silt_C in Figure 1) determined using the usual technique of reconstituted loose samples tested in drained and undrained triaxial compression. The points shown in Figure 5 as large dots are the identified critical state of each test. The CSL for the stress range of $30 \mathrm{kPa}<p^{\prime}<1500 \mathrm{kPa}$ is sensibly fitted with the usual semi-log idealisation

1. $e_{\mathrm{c}}=\Gamma-\lambda_{10} \log \left(p^{\prime}\right)$

Table 1 gives the numerical values for the soil properties $\Gamma$ and $\lambda_{10}$ for the silts whose gradations are shown in Figure 1. Broadly, the property $\lambda_{10}$ represents a soil's intrinsic compressibility and the tabulated values are midway between clean sands $(\sim 0.05)$ and plastic clays $(\sim 0 \cdot 3-0 \cdot 5)$, an unsurprising situation for silts.
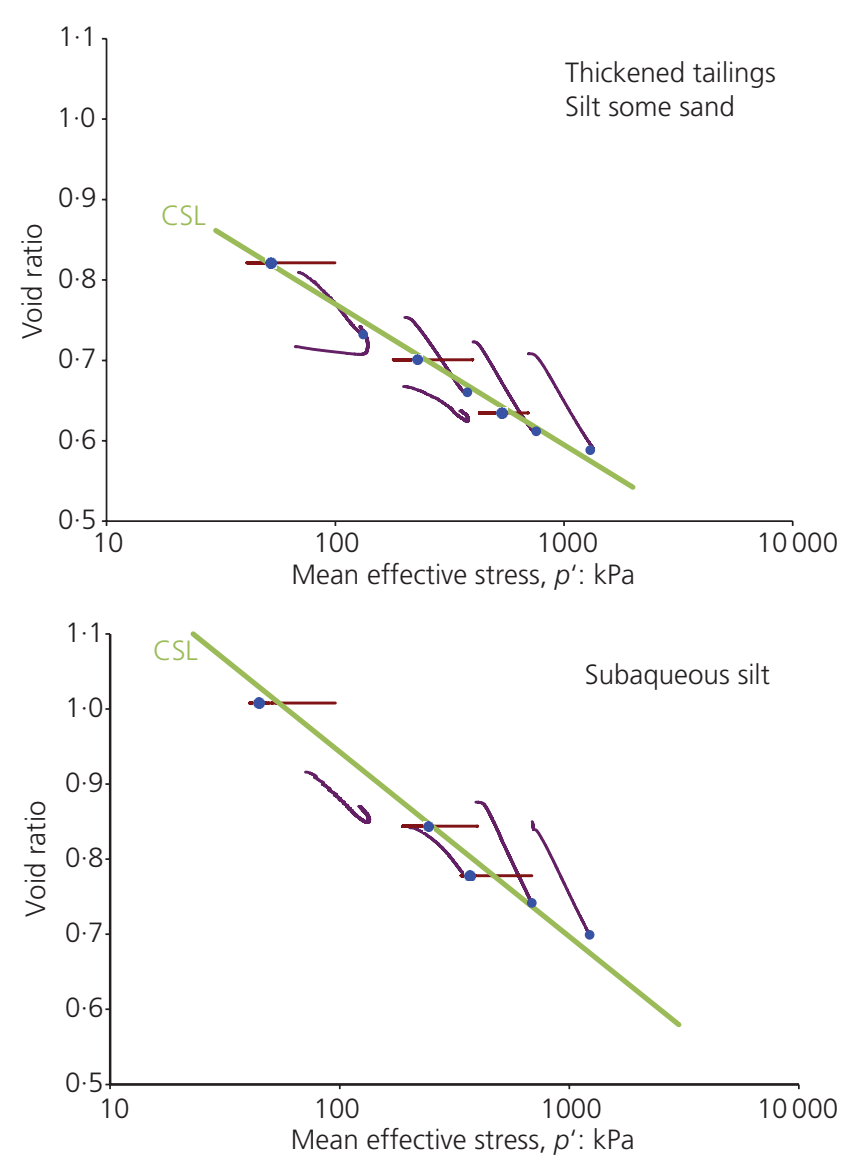

Figure 5. Examples of CSL in silts (blue dots denote assessed critical state of each test where that state was reached)

\section{Stress dilatancy}

Alongside the CSL, stress dilatancy is a fundamental behaviour of particulate materials. Figure 6 shows the results of three drained 


\begin{tabular}{|c|c|c|c|c|c|c|c|}
\hline & Silt A & Silt B & Silt C & Silt D & Silt $E$ & Silt $F$ & Silt G \\
\hline \multicolumn{8}{|c|}{ Critical state } \\
\hline$\Gamma$ & 1.076 & 1.423 & $1 \cdot 115$ & $1 \cdot 305$ & 1.900 & $2 \cdot 120$ & 1.420 \\
\hline$\lambda_{10}$ & 0.159 & 0.246 & 0.175 & 0.200 & 0.480 & 0.550 & 0.180 \\
\hline $\begin{array}{l}M_{\mathrm{tc}} \\
\text { Dilatanc }\end{array}$ & $1 \cdot 25$ & $1 \cdot 35$ & $1 \cdot 40$ & $1 \cdot 20$ & $1 \cdot 37$ & $1 \cdot 26$ & $1 \cdot 31$ \\
\hline$N$ & $0 \cdot 30$ & $0 \cdot 30$ & $0 \cdot 30$ & $0 \cdot 30$ & 0.00 & 0.40 & 0.30 \\
\hline $\begin{array}{l}\chi_{\mathrm{tc}} \\
\text { Plastic h}\end{array}$ & 4.0 & $2 \cdot 5$ & $2 \cdot 5$ & $2 \cdot 0$ & 0.8 & $2 \cdot 5$ & $2 \cdot 5$ \\
\hline $\begin{array}{l}\mathrm{H} \\
\text { Elasticity }\end{array}$ & 25 & $20-100 \psi$ & $30-200 \psi$ & 45 & 30 & $17-100 \psi$ & 50 \\
\hline A: MPa & a & $3 \cdot 7$ & 8.0 & a & $3 \cdot 5$ & a & a \\
\hline$b$ & - & 0.50 & 0.60 & - & 0.40 & - & - \\
\hline$e_{\min }$ & - & 0.60 & 0.35 & - & 0.50 & - & - \\
\hline$I_{r}$ & 100 & 60 & - & 100 & - & - & 125 \\
\hline$v$ & 0.15 & $0 \cdot 20$ & $0 \cdot 10$ & 0.20 & 0.2 & 0.2 & 0.15 \\
\hline
\end{tabular}

${ }^{\text {a }}$ Only in situ data available; see Figure 8 for the trend used, which is only a function of stress

Table 1. Calibrated properties of silts

triaxial compression tests on a loose silt with the data transformed to stress-dilatancy space; although the stress-dilatancy theory involves plastic strain increments, here total strain increments are used in computing the dilation $D$ - this is an approximation to the true situation, but elastic strains are a small component of drained compression, and this simple algebraic transformation gives a 'quick look' at the soil behaviour with minimal effort. Also shown in Figure 6 is a trend line given by Nova's (1982) stress-dilatancy rule

2. $D \approx D^{\mathrm{P}}=(M-\eta) /(1-N)$

where $M$ and $N$ are soil properties. Nova's flow rule is an idealised dissipation of plastic work into heat, with Nova's rule implying inelastic energy storage in addition to the plastic work dissipated by the plastic shear strain (Jefferies, 1997). The trend line was fitted using $M=1.35$ and $N=0.30$; these are values that are comparable to those found with recently crushed sands. The original Cam Clay flow rule is simply Nova's rule with the property $N=0$. The mismatch between test data and Nova's flow rule for $\eta<0.4$ also arises with sands and appears caused by the sample reconstitution procedures inducing some overconsolidation, with the result that the initial loading is elastic.

\section{State dilatancy}

The trend relating peak friction angle $\phi$ and $\psi$ identified by Been and Jefferies (1985) has been widely used. However, it is not the best way of representing that aspect of soil behaviour because, as originally identified by Bishop (1950), the dilational component of strength adds to the intrinsic soil friction - what today is called the property $M_{\mathrm{tc}}$. $M_{\mathrm{tc}}$ varies from one soil to another depending on, at least, the particle shape and particle mineralogy. There is the further view that dilation is a kinematic behaviour. Thus, a better expression for the effect of state on soil behaviour is as a limiting dilation rather than peak strength

\section{3. $D_{\min }=\chi \psi$}

where $\chi$ is a soil property. Been and Jefferies (1985) used the initial value $\psi_{0}$ at the start of test, which is questionable mechanics in general, as everything should be expressed in terms of current, not initial, values - hence, the more general use of $\psi$ in Equation 3 (and which means a tad more processing when reducing test data to soil properties). Figure 7 shows an example of data from drained triaxial compression tests plotted in this way,

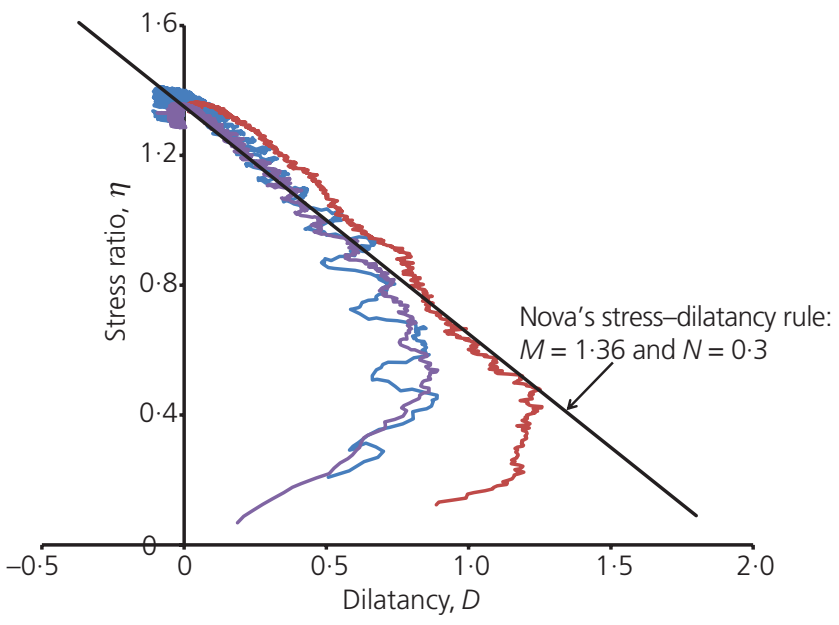

Figure 6. Stress dilatancy in loose silts 


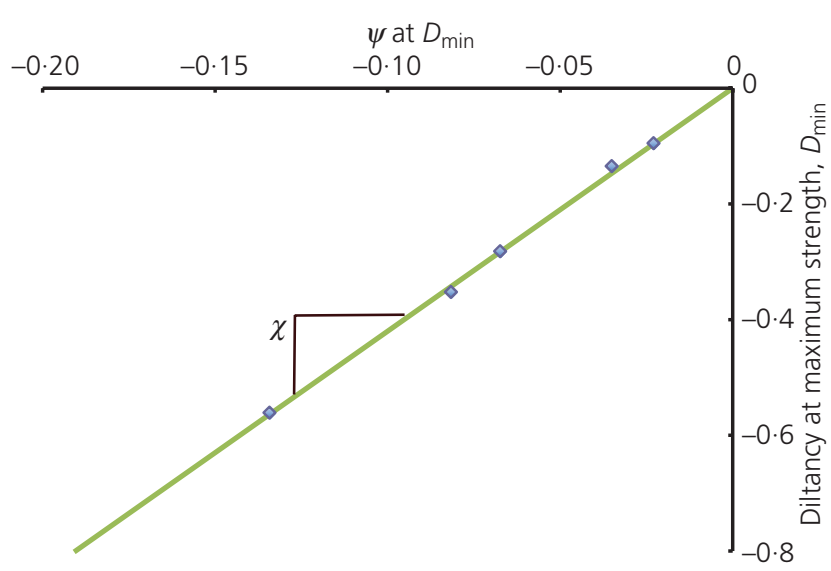

Figure 7. State dilatancy of Nerlerk sand

with a clearly defined trend and little scatter. The proposition of Been and Jefferies (1985) amounts to $\chi \approx 4$ for a wide range of sands with less than $<20 \%$ fines; today, this proposition remains acceptable for that range of soils but additional accuracy is gained, and the framework extended to all soils, if $\chi$ is treated as a soil property rather than a universal constant.

The dilation rate defined by $D_{\min }$ is directly related to the familiar maximum dilation angle $\delta$. For the case of triaxial compression with its symmetry $\left(\varepsilon_{2}=\varepsilon_{3}\right)$

4a. $\sin (\delta)=-3 D_{\min } /\left(6-D_{\min }\right)$

or, on substituting Equation 3 into Equation 4a

4b. $\sin (\delta)=-3 \chi \psi /(6-\chi \psi)$

Equation $4 \mathrm{~b}$ emphasises the linkage between $\psi$ and $\delta$, and in some ways these two parameters are almost identities of each other. The leading minus sign is a consequence of dilation being a negative strain rate for the usual compression positive convention of soil mechanics.

A small difficulty now develops that is particular to silts. The soil property $\chi$ is ideally determined from drained triaxial compression tests on dense samples with a range of void ratios and confining stress - such data require no constitutive model, and it is simply a case of an algebraic conversion of measured strain increments into dilation (elastic strain rates are zero at peak strength in drained triaxial compression, making data processing for this soil property independent of elasticity). Figure 7 is for sand and was developed this way. The difficulty with silts is that the present procedures for reconstituting silt samples do not produce the range of void ratios encountered on-site, producing silt samples that are both not as loose and not as dense as those that naturally occur. Plots such as Figure 7 are difficult to produce for silts. This leaves $\chi$ as a property that must be determined through iterative forward modelling of test data, illustrated shortly, and which does not have the precision of simply plotting results from a wide range of initial states; it also requires a constitutive model, and that choice may affect the precision/bias of the determined value for the property. As quick comparison, silts show about half the $\chi$ values as those of sands, plausibly reflecting the greater void space of silts and their greater compressibility.

\section{Plastic hardening}

The soil properties $\Gamma, \lambda, M, N$ and $\chi$ are all associated with soil behaviour that can be seen from plotting triaxial test data in various ways - no constitutive model is involved, and the properties are familiar and simply defined. Plastic hardening, however, is different in that there is no accepted property for describing this behaviour. The Cam Clay variants avoid issues about plastic hardening by linking that hardening to the slope of the CSL (i.e. hardening $\approx 1 / \lambda$ ). But all state-based models decouple their yield surfaces from the CSL - which is how they gain the capability of computing the spectrum of soil behaviour. This then leads to a need to define a plastic modulus; but the absence of a generally accepted soil property leaves each model with its own choice about how to characterise and represent this aspect of soil behaviour.

NorSand uses the dimensionless hardening modulus $H$ as its property, this property being defined from its role in the hardening law - see the Appendix. Conceptually, $H$ is related to the initial slope of a drained, isotropic triaxial compression stress-strain curve, with that initial stiffness normalised by the confining stress to make it dimensionless.

\section{Elasticity}

Elasticity is now commonly measured using geophysical methods. The principle is to determine the velocity of an elastic shear wave by using polarity reversal techniques to distinguish the shear wave from the faster-propagating compression wave. This elastic shear wave velocity is then converted to the elastic shear modulus (generally referred to as $G_{\max }$, courtesy of the strain-dependent modulus viewpoint) by using the equations of isotropic elasticity (i.e. $G_{\max }=\rho V_{\mathrm{s}}^{2}$ ). In the case of laboratory tests, transducers ('bender elements') are mounted in the platens of the triaxial cell to measure the wave propagation velocity. In the case of in situ tests, it is now usual to mount the receiver as an additional transducer in the CPT with a signal source at surface (a.k.a. vertical seismic profiling). The simplicity and repeatability of shear wave velocity measurements has seen their rapid migration from research technique to routine engineering practice.

Data on of the elastic shear modulus of silts is presented in Figure 8 (the same silts whose gradation is in Figure 1). This includes both in situ and laboratory measurements. Also shown for comparison is a trend for compact Ticino sand. Three things stand out: silt modulus is affected by stress level and void ratio; the silt trends are comparable to those of sands; and laboratory and field measurements produce similar values. The idea that silts are just extra fine sand is reinforced. 


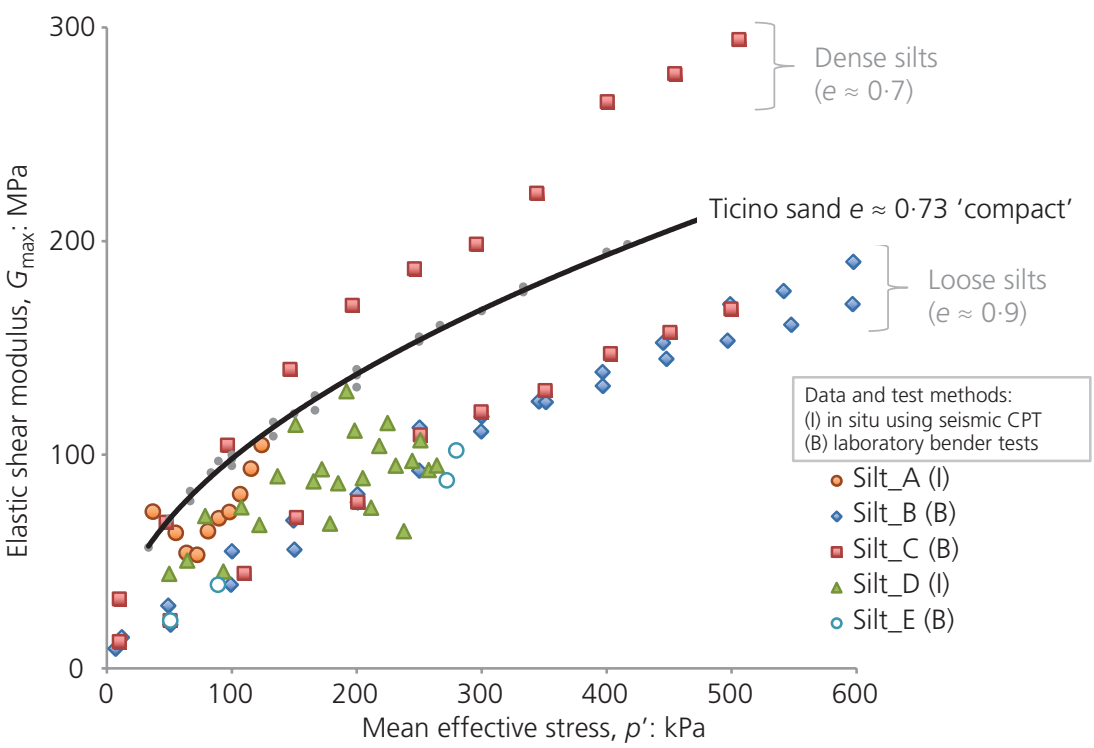

Figure 8. Elastic shear modulus of silts

Knowledge of $G_{\max }$ alone is insufficient for modelling soils in general. For incompressible pore fluid, using the elastic-plastic strain decomposition, the undrained condition is

5. $\quad \mathrm{d} \varepsilon_{\mathrm{v}}=\mathrm{d} \varepsilon_{\mathrm{v}}^{\mathrm{e}}+d \varepsilon_{\mathrm{v}}^{\mathrm{p}}=0$

On substituting for the elastic volumetric strain increment by using the elastic bulk modulus $K_{\max }$, the change in excess pore pressure $\mathrm{d} u$ during undrained shear is obtained

6. $\mathrm{d} u=K_{\max } \mathrm{d} \varepsilon_{\mathrm{v}}^{\mathrm{p}}$

Thus, accurate modelling of excess pore pressure, using any plasticity model, requires accurate knowledge of $K_{\max }$. Note that in plasticity models, there can be no 'strain-dependent elasticity', as this aspect of soil behaviour is captured by the plastic strains themselves. This presents a further challenge, as $K_{\max }$ can be determined only by using seismic wave propagation methods for unsaturated soils because the compression wave velocity is dominated by the stiffness of the pore water, not the soil matrix elasticity. Broadly, three approaches are found in practice: (a) using $K_{\max }$ to fit the modelled stress path to data; (b) relating $K_{\max }$ to $\lambda$ or $(c)$ relating $K_{\max }$ to $G_{\max }$ and $v$.

The approach of using $K_{\max }$ to fit the model to undrained tests uses the fact that elasticity has a smaller effect when fitting a model to drained tests than it does in fitting undrained tests - and which then allows fitting drained tests to determine the plastic hardening. This plastic hardening cannot change between drained and undrained paths (because undrained paths are a consequence of a change in boundary condition), so that $K_{\max }$ is then used as a 'free' parameter for modelling the excess pore pressure to obtain the best fit to the measured stress path by using Equation 6. This approach offers simplicity, albeit with some iteration between drained and undrained fits.

The second approach to $K_{\max }$ views isotropic compression behaviour as the appropriate way of assessing the soil's bulk modulus. Isotropic or oedometer compression tests are used with unload-reload cycles to distinguish the first loading response from swelling/reloading - giving the familiar soil properties $C_{\mathrm{c}}$ and $C_{\mathrm{s}}$ or, equivalently as used in Cam Clay variants, $\lambda$ and $\kappa$. Wroth (1984) reported extensive tests on the strength of overconsolidated clays that were closely modelled using Modified Cam Clay with $\kappa / \lambda=$ $0 \cdot 2$, this ratio then being viewed as a universally applicable constant. The relation between $\kappa$ and $K_{\max }$ is

7. $K_{\max }=p(1+e) / \kappa$

The problem with both these approaches to determining $K_{\max }$ is that they often hide physically implausible (i.e. negative) Poisson's ratios.

The third approach is more fundamental in that it treats the geophysical measurement of $G_{\max }$ as having independently determined this property. The bulk modulus $K_{\max }$ is then related to $G_{\max }$ through isotropic elasticity

8. $K_{\max }=G_{\max } \frac{2(1+v)}{3(1-2 v)}$

assuming that Poisson's ratio $(v)$ is constant for any soil. Thus, the two elastic moduli $\left(G_{\max }\right.$ and $\left.K_{\max }\right)$ can depend on void ratio and stress, but they do so without violating physical laws (energy is conserved around a loading loop). Practically, it is assumed that 
Poisson's ratio can be measured on dry samples and its value is unchanged by saturation. The most comprehensive study is Bellotti et al. (1996), who investigated Ticino sand, and their data indicates $v \approx 0.2$ (Jefferies and Shuttle, 2002). There appear to be no investigations into $v$ for silts (in part because current reconstitution procedures inevitably produce saturated samples). The value $v=0 \cdot 15$ has been simply adopted as 'not unreasonable' given other issues about the magnitude of $K_{\max }$ that will be discussed shortly.

\section{Representing silt behaviour with NorSand}

Interestingly, despite what appears to be very different strengths and compressibilities, the physical and mathematical representation of sand and clay behaviour is common. A range of constitutive models exist, differing in their details, but since about 1990, it is the models that are framed around the concepts of critical state soil mechanics (which is a lot more than either variant of Cam Clay) that have become dominant. Such models are 'good' in the sense that adopting a CSL allows these models to predict the effect of void ratio and confining stress on soil behaviour for all stress paths and loadings. From the practical perspective, only a few soil properties are needed, which are both dimensionless and constant for any soil.

All such state-based models build on the critical-state concepts and theory developed over the past 70 years and use the state parameter $\psi$ to relate strength and stiffness to the CSL. Simple insight into soil behaviour is offered, often with remarkable accuracy. State-based models represent a long-established framework for understanding mechanical aspects of soil behaviour by using work-hardening plasticity with substantive contributions from both the USA and the UK (see Jefferies and Been (2015) for a historical perspective). The key aspects of state-based models are $(a)$ the yield surface, $(b)$ the 'flow rule' giving relative plastic strain increments and which invokes stress dilatancy and (c) the hardening law which controls how the yield surface responds to plastic strain. NorSand (Jefferies, 1993) was the first of these state-based models, and its equations are summarised in the Appendix; NorSand accurately captures the entire spectrum of soil behaviour from dilation of dense soils to extreme liquefaction of very loose ones. Original Cam Clay (Schofield and Wroth, 1968), with its very limited range of soil behaviours, exists as a special case of NorSand by using a particular choice of soil properties and initial conditions (see appendix H of Jefferies and Been (2015)).

The soil properties used in NorSand are largely familiar (i.e. most are not specific to NorSand), with some flexibility depending on the level of detail sought. Some of these soil properties have already been introduced in the earlier discussion of silt behaviour. All properties are determined by triaxial compression tests, with the mathematics of NorSand handling the generalisation to threedimensional (3D) stress conditions (Jefferies and Shuttle, 2002). In the simplest form, three properties $\left(M_{\mathrm{tc}}, \Gamma, \lambda\right)$ are used to define the critical state (on current evidence, there is no need for anything other than a semi-log CSL with silts). Two properties are associated with strength at peak dilatancy: $N$, the volumetric coupling following Nova (1982), and $\chi$, determining the influence of $\psi$ on maximum dilatancy; these are the two properties introduced earlier. The plastic hardening modulus $H$ is needed because the yield surface is decoupled from the CSL, although there is an approximate proportionality of $H \approx 2 / \lambda$ echoing aspects of the Cam Clay variants.

In terms of elastic shear modulus, the simplest approach uses just two properties, $I_{\mathrm{r}}\left(=G_{\max } / p^{\prime}\right)$ and $v$, but this is not particularly accurate, as soils generally have a non-linear dependence of elastic shear modulus on the stress level. There is a further effect of void ratio on elastic modulus. Equally, because all current good models are elasto-plastic, there is no 'strain dependence' of elastic modulus (a fact easily demonstrated by using bender elements during triaxial shear). A physically plausible idea is that the volumetric compressibility should tend to zero as a soil tends to its minimum void ratio (e.g. as a sand becomes so dense that it transitions into sandstone). Data suggest that quartz sands follow such an idealisation (Jefferies and Been, 2000). If the further idealisation of constant Poisson's ratio is adopted, this gives a relation under isotropic elasticity that

9. $G_{\max }=\frac{A}{\left(e-e_{\min }\right)}\left(\frac{p^{\prime}}{p_{\text {ref }}}\right)^{b}$

where $A, e_{\min }$ and $b$ are the soil properties of isotropic elasticity. The parameter $p_{\text {ref }}$ is the mean effective stress used to bring Equation 9 to a dimensionally convenient form, by convention taken as $p_{\text {ref }}=100 \mathrm{kPa}$.

Calibration procedures for determining sand properties are presented in Jefferies and Shuttle (2005), with further details in Jefferies and Been (2015). Nothing unusual is needed with all sand properties being readily found in normal engineering practice by using reconstituted samples. Silts present more challenges, arising from the inability of the present laboratory procedures to reconstitute silt samples over the range of void ratios found in situ.

Silt samples consolidated from slurry readily give data sufficient to define a CSL - the paths shown in Figure 5 are from such samples, and examples of the measured stress-strain behaviour in drained and undrained triaxial compression are shown in Figure 9. The end point of these tests also provides $M_{\mathrm{tc}}$. The difficulty arises with the properties $N$ and $\chi$, which are most clearly and accurately defined if there are triaxial compression tests on dense samples - exactly the same dense samples that have proved difficult to create in the laboratory with present procedures. Although $N$ is best found from a plot of $\eta_{\max }$ against $D_{\min }$ for several dense drained tests, this property is embedded in the stress-dilatancy law that applies throughout the loading and regardless of void ratio; thus, fitting a trend line through drained test data that have been transformed to stress-dilatancy space gives an estimate of $N$ (Figure 6). The property $\chi$ is problematic as when $\psi \approx 0$, the property has no effect - see Equation 3. The procedure that is followed to refine $N$ and to determine $\chi$ is 'iterative forward modelling'. 

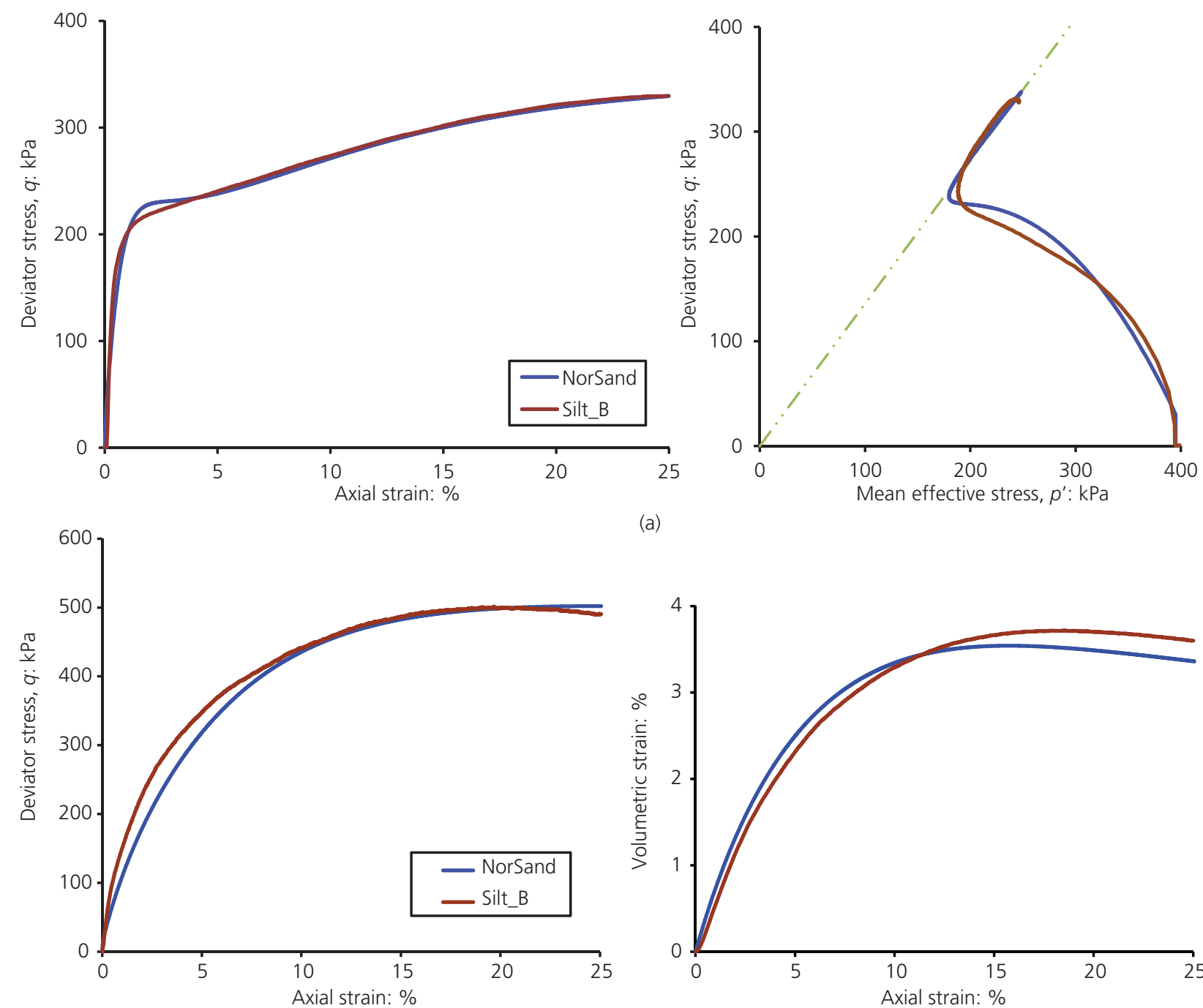

(a)

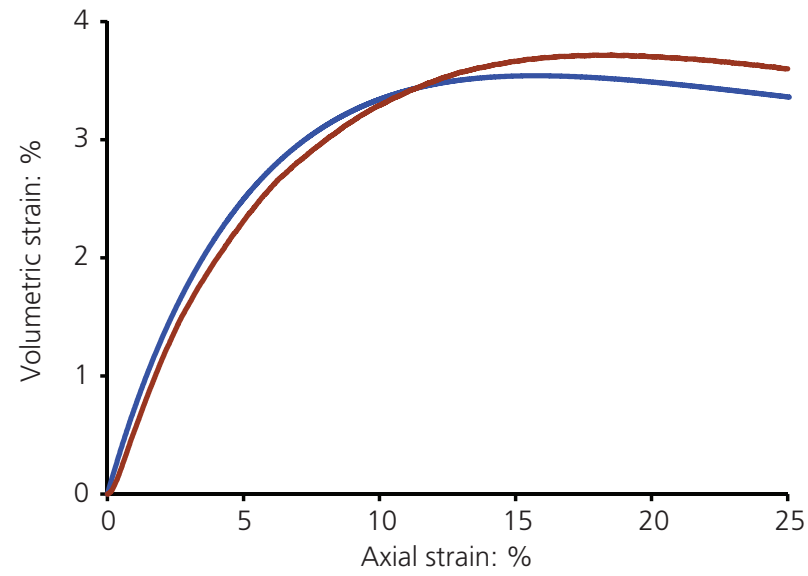

(b)

Figure 9. Comparison of NorSand with reconstituted silt behaviour in (a) drained and (b) undrained triaxial compression (Silt_B, properties as per Table 1)

Iterative forward modelling is a procedure where the complete set of parameters/properties is estimated (and some, such as the initial void ratio and test confining stress, will be known) and the entire stress-strain behaviour computed. The computed behaviour is compared to that measured, and the properties revised to improve the fit. Repeating the procedure ('iterating') to obtain a match between computed and measured values provides best estimates of the properties. In the case of NorSand (and other good soil models), it is easy to program them in a spreadsheet by using numerical Euler integration (a simple method whose small step size is no limitation when dealing with triaxial test data). Figure 9 also shows fits of NorSand to the drained and undrained triaxial tests on silt, these fits being obtained by such iterative modelling. As it is slightly tedious to program constitutive models, the spreadsheet implementing iterative modelling of triaxial compression tests using NorSand is a Supplementary Material downloadable file from this journal's website.

Iterative modelling requires a criterion as to what is an acceptable fit of model to data. Although various statistical measures might be adopted, not all parts of a stress-strain curve are of equal value for example, peak strength is important, but the exact strain at which this is achieved might reasonably be regarded as less important than getting a reasonable match to the general shape of the stress-strain curve. It is also important to get a reasonable match to the volumetric strain or, equivalently, the stress path for undrained tests. Experience suggests that most engineers recognise what is reasonable, and there is only a small difference in views over the chosen best fit; accordingly, formal statistical best-fit criteria are avoided in preference to engineering judgement. 
Iterative modelling works best when each of the parameters being iterated has a distinct effect on the computed behaviour. Minimising the number of parameters being iterated also greatly improves the efficiency of iterating. In the case of any good model, $\Gamma, \lambda$ and $M$ should be determined directly from test data and there is no difficulty in doing this (as shown earlier for silts). This leaves $H$, and for silt $\chi$ and $N$, to be found by iterating. In practice, NorSand is tolerably easy to fit to any test with one interesting niggle - it is rare to find that peak dilation and peak strength coincide in test data, as expected from stress-dilatancy theory, and NorSand is usually best fitted by focusing on the volumetric strain rather than peak strength.

Although these concerns about the iterating procedure might suggest that iterating leads to uncertain values for the soil properties, such a concern misses an important attribute of the method: this formal modelling is an optimisation of the soil properties across the whole data set. The key offering of all good models is that their properties do not change with void ratio or confining stress, which means that the same property values must be used for every test in the data set. Iterative forward modelling forces recognition of just how well the chosen model replicates the entire set of measurements.

As a final comment on fitting NorSand to triaxial data on silts, there is a general issue with $K_{\max }$. The three alternative methods for determining $K_{\max }$ were discussed earlier. The most fundamental approach appears to estimate $K_{\max }$ from the geophysically measured $G_{\max }$ by way of Equation 8 using a constant, plausible Poisson's ratio; in the case of the silts considered, the $G_{\max }$ data from Figure 8 are adjusted for initial void ratio as per Equation 9. An example of applying this choice for $K_{\max }$ to an undrained test in silt is shown in Figure 10, all other properties being at their best-fit values. Figure 10 also shows the results of the undrained test being modelled for comparison. As can be seen, using such a geophysically based $K_{\max }$ produces a too-stiff initial response, which then develops into a sharp transient loss of strength followed by strong dilation to the correct critical state - the computed behaviour is nothing like that measured. Resorting to the first approach, where the elastic stiffness is reduced to match the measured undrained stress path, produces a rather good fit to all aspects of the actual test, as also shown in Figure 10; this reduced elastic stiffness corresponds to $K=K_{\max } / 4$, and $G$ was reduced proportionally at the same time to maintain Poisson's ratio at $v=0 \cdot 15$. It is emphasised that both of these simulations had identical values for the other properties and which were derived from the calibration discussed earlier. Interestingly, if this reduced $K$, and the associated $v \approx 0 \cdot 15$, is used to compute the volumetric elasticity by using Equation 7 ; the resulting ratio $\kappa / \lambda \approx 0.25$ for this silt, not far off the optimised 'universal' ratio $\kappa / \lambda=0 \cdot 2$ for overconsolidated clays reported by Wroth (1984). The presented undrained fit in Figure 9 had the reduced $K$.

Interestingly, the difficulties with $G_{\max }$ and $K_{\max }$ are not restricted to silts - the same troubles arise with sands. The implication is that the elasticity of the soil skeleton is systematically different from the elasticity applying to the transmission of seismic waves through the soil. The systematic divergence appears, on current modelling, to be the same across the various silts and sands considered - which makes it easy enough for the practical engineer to continue with the simple, repeatable procedures of measuring shear wave velocity and then to scale simply the data. Fundamentally, however, it does raise questions that ought to be investigated.

\section{CPT resistance in sands: calibration studies}

As will be seen shortly, there are several idealisations of questionable reasonableness in theoretical approaches to CPT resistance - and which correspondingly lead to uncertainties in the assessed soil state from CPT data. It is helpful to consider first the calibration of CPT to the sand state before looking at the theory as these calibrations define, for their particular soil properties and conditions, what should be expected. It is necessary to look at the sand data, as there are no complete calibration studies for the CPT in silt.
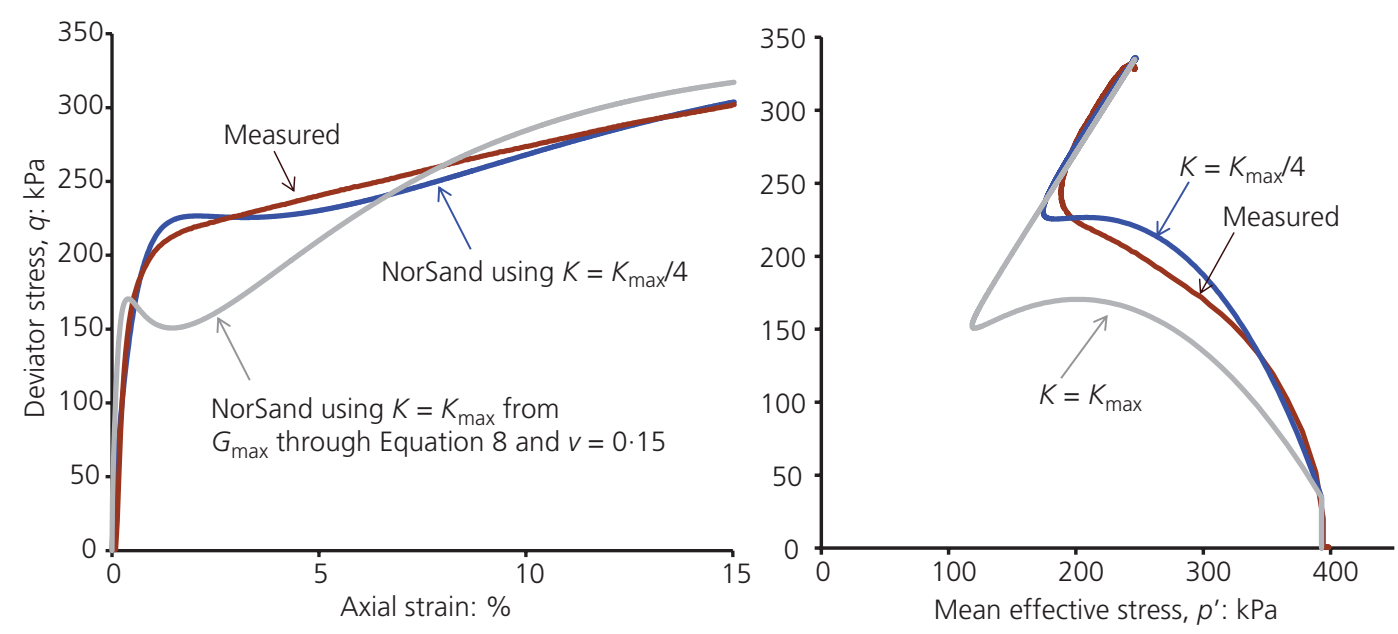

Figure 10. Effect of elastic bulk modulus on computed silt behaviour 
CPT calibration chambers are, in effect, a giant triaxial cells in which a CPT is pushed into a sand of known void ratio and under known stress. Repeating the procedure with many samples of the same sand provides a mapping between tip resistance, soil state and stress level. Most members of the in situ testing community regard chamber calibration of the CPT as the 'gold standard' for interpreting CPT data. The only difficulty in this is that each chamber test involves careful placement of as much as $2 t$ of sand, so it is not commercially viable for most projects. Chamber tests tend to be research programmes by universities, with just a few contributions from the industry; the paper of Jefferies and Been (2015) is a convenient summary of all this calibration chamber data.

The starting point for determining the state parameter from the CPT was this worldwide set of chamber tests, with samples of the sands used being then tested to determine their CSL (Been et al., 1986). Combining the void ratio of each calibration test with the appropriate CSL for that sand produced a relation between normalised CPT resistance $Q$ and the initial state parameter $\psi_{0}$ (i.e. the soil state before pushing the CPT); Figure 11 shows an example of such a transformation of calibration chamber data for Erksak sand (data from Been et al., 1987a). The trends shown in Figure 11 can be fitted with an equation

$$
Q_{\mathrm{p}}=k \exp (-m \psi)
$$

or in its inverted form used to evaluate CPT data

10. $\psi=-\ln \left(Q_{\mathrm{p}} / k\right) / m$

where $Q_{\mathrm{p}}=\left(q_{\mathrm{t}}-p_{0}\right) / p_{0}^{\prime}$ and is the dimensionless CPT resistance (the subscript ' $\mathrm{p}$ ' is used to denote the use of mean, not vertical, stress; the corresponding $Q$ found in much of the in situ testing literature uses the vertical stress).

There is some scatter apparent in Figure 11 and also a small systematic bias. The scatter develops because, although calibration

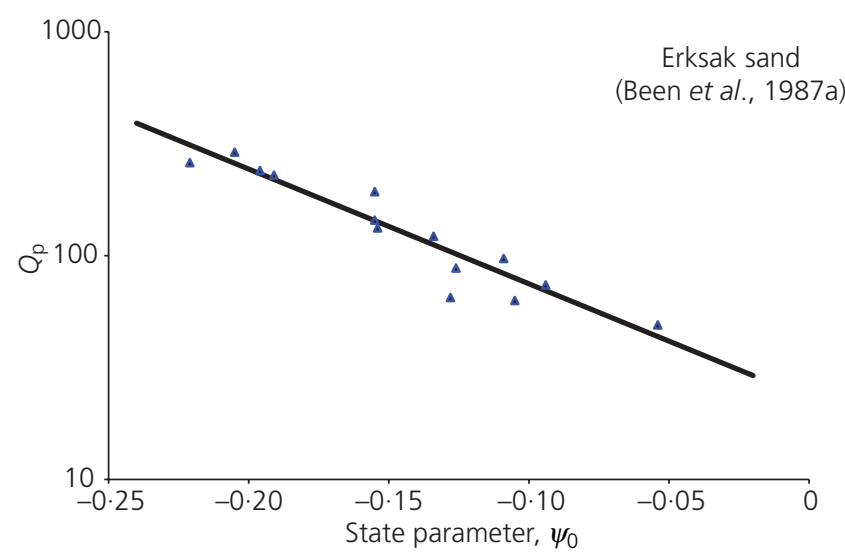

Figure 11. Normalised CPT resistance in calibration chamber test of Erksak sand chamber data are treated as the gold standard, the reality is that each data point involves an 'eyeballed' pick of the representative $q_{\mathrm{t}}$ (which is rarely the desired uniform tip resistance with depth) as well as the accuracy of determining the void ratio of $1-2 t$ of sand (however carefully placed). The systematic bias arises because calibration chamber tests are carried out over a range of confining stresses, and when $q_{\mathrm{t}}$ is normalised by confining stress into $Q$, the data at low confining stress tend to plot to the top of the data bandwidth in Figure 11, with the high-stress data plotting to the bottom of this bandwidth; this point was addressed by Shuttle and Jefferies (1998) and arises because elastic shear modulus increases less rapidly with confining stress than a simple linear trend. A further accuracy reduction is that the CPT resistance is influenced by soil extending as much as $1 \mathrm{~m}$ from the probe - most chamber tests results need correcting for the finite chamber size, and these chamber size corrections are not without their own controversies.

The results of all existing chamber test programmes are described by Equation 10 but with the coefficients $k$ and $m$ depending on the soil's properties as well as $I_{\mathrm{r}}\left(=G_{\max } / p_{0}^{\prime}\right)$. The coefficients $k$ and $m$ will be discussed again after theoretical approaches to the CPT resistance are described.

\section{Cavity expansion as analogue of CPT}

\section{Background}

Cavity expansion involves, as the name suggests, expansion of a cavity by internal pressure in either finite or infinite media. As in many things, the initial impetus was military, with the cavity being battleship gun barrels of the early twentieth century. But the interest here is the mechanics, as the extreme symmetry of cylindrical or spherical cavity expansion allows a 3D situation to be described in terms of one variable (radius to a point in the domain), while the kinematic constraints enforce constant direction of principal stresses and strains. Originally, this symmetry allowed closed-form solutions for some constitutive models under finite deformations (a.k.a. large strain); this work underlies many design formulae for deep foundations and in situ testing, the CPT in particular. The basic idea can be expressed as

11. $Q_{\mathrm{p}}=C_{\mathrm{Q}} Q_{\mathrm{sph}}$

where $Q_{\mathrm{p}}$ is the dimensionless CPT tip resistance, $Q_{\mathrm{sph}}$ is the limit pressure of the soil in spherical cavity expansion and $C_{\mathrm{Q}}$ is the mapping factor (ideally a constant, but in principle something that might depend on dilation and/or the friction ratio measured by the CPT).

Bishop et al. (1945) derived the limit pressure for expansion of spherical cavity in an infinite medium of Tresca material and suggested that the pressure required for a punch to indent metal to greater than three punch diameters was related to this cavity expansion limit pressure - this is the first statement of the idea represented by Equation 11. Gibson (1950) suggested that since 
the undrained strength of clay $s_{\mathrm{c}}$ approximates a Tresca material, the Bishop et al. (1945) result could be adapted for calculating the end bearing capacity of piles in clay by allowing for the additional shear force along the pile tip that acts in addition to the normal stress that is taken to be the spherical cavity limit pressure $\left(P_{\text {lim }}\right)$. This idea has become standard, and is also applied to end bearing of piles in sand. The general scheme is shown in Figure 12. The difference between clay and sands is that this shear force on the tip is an additive component to the spherical limit pressure for clays, while it is a multiplier for sands. Choosing the standard CPT geometry with $\alpha=60^{\circ}$ gives

12a. 'clay' (undrained, Tresca): $q_{\mathrm{t}}=P_{\lim }+3^{1 / 2} s_{\mathrm{c}}$

$$
\begin{aligned}
& \text { 'sand' (drained, Mohr-Coulomb): } q_{\mathrm{t}} \\
& \text { 12b. }=P_{\mathrm{lim}}+\left(1+3^{1 / 2} \tan \phi_{\mathrm{c}}\right) \approx 2 P_{\mathrm{lim}}
\end{aligned}
$$

where the condition is added that soils at the interface with the CPT will be in their critical state (subscripted by 'c') because of large shear strains induced in this zone. The approximation given for sand uses $\phi_{\mathrm{c}}=31^{\circ}$, a reasonable value for natural subrounded quartz sands. The approximate scaling of the cavity limit stress in sand corresponds to $C_{\mathrm{Q}} \approx 2$, which is consistent with the experimental results of Landanyi and Roy (1987).

The solution for expansion of a cavity in a Tresca material exploited the constant volume behaviour of this material, which gives a simple relation between the strain increments everywhere in the domain and cavity wall movement. Clearly, sands (and more generally, all soils under drained loading) do not exhibit zero volumetric strain increments - these volumetric strains, and a

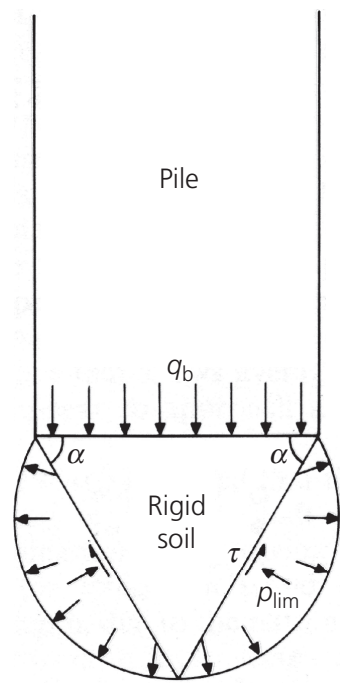

Figure 12. Postulated relation between cavity limit pressure and pile resistance (Randolph et al., 1994) dependence of yield on confining stress, are what distinguishes particulate materials from metals. Arguably, the most fundamental behaviour of soils is dilation with deformation (Reynolds, 1885); Rowe (1962) showed by way of micromechanical considerations that stress-dilatancy behaviour is intrinsic to an assembly of interacting particles (although this does not imply that Rowe's stress-dilatancy rule must be used - there are alternatives, derived from idealised plastic work dissipation models). The difficulty with stress dilatancy is that it is incremental, which in terms of obtaining a cavity limit pressure requires integration throughout the domain and throughout time.

The first satisfactory solution for cavity expansion in a nonassociated Mohr-Coulomb (NAMC) soil was that of Carter et al. (1986), and this solution remains widely used today (it is used later in this paper for verification of the adopted numerical procedures). The attraction of NAMC is that the dilation angle $(\delta)$ is different from the friction angle $(\phi)$, allowing simulation of soil behaviour over a wide range of soil densities. The NAMC soil is elastic-perfectly plastic with four properties: $\phi_{\mathrm{c}}, \delta, G$ and $v$. In practice, when NAMC is calibrated to drained triaxial tests, $G$ is often taken as a quasi-elastic secant modulus to peak strength.

\section{Solutions with CPT geometry}

Since the development of the finite-element method, purely numerical approaches using actual CPT (or pile) geometry have become possible. However, finite-element analysis of the CPT is extraordinarily difficult - which is why so few studies exist. The challenge in finite-element studies is that, within geomechanics, finite-element analysis is formulated in terms of stress and (usually, small) strain. Whereas the CPT presents a 'flow' problem closer to those found in hydraulics than geomechanics and where it would be clearer to discuss the situation in terms of velocities rather than displacements. Some work has indeed gone in this direction with the 'strain path method' (Baligh, 1985; Teh and Houlsby, 1991), but only for Tresca soil (a zero-volumetric strain material) and with considerable approximations in the solution method.

There are, as yet, few studies for CPT penetration in NAMC soil. Willson et al. (1989) provided some early results, but they introduced a double-hardening cap to deal with compressibility, making their results difficult to compare with cavity expansion solutions to assess the consequence of real CPT geometry. A most interesting study using actual CPT geometry in NAMC soil is that of van den Berg (1994); Figure 13 compares some of van den Berg's results with the Carter spherical cavity solution for exactly the same NAMC properties. Broadly, van den Berg's results suggest that $C_{\mathrm{Q}} \approx 4$, which is double that inferred in the previously discussed work. However, there are two cautions about van den Berg's results: $(a)$ the elastic modulus used was remarkably soft for sand-like behaviour, with the results shown in Figure 13 being for $I_{\mathrm{r}}=55$, and $(b)$ too much load was being introduced into the shearing zone by excessive shaft friction with these simulations having $2 \cdot 2 \%<F<2 \cdot 6 \%$, which is about five times larger than found in CPT penetration of clean to somewhat silty sands. 


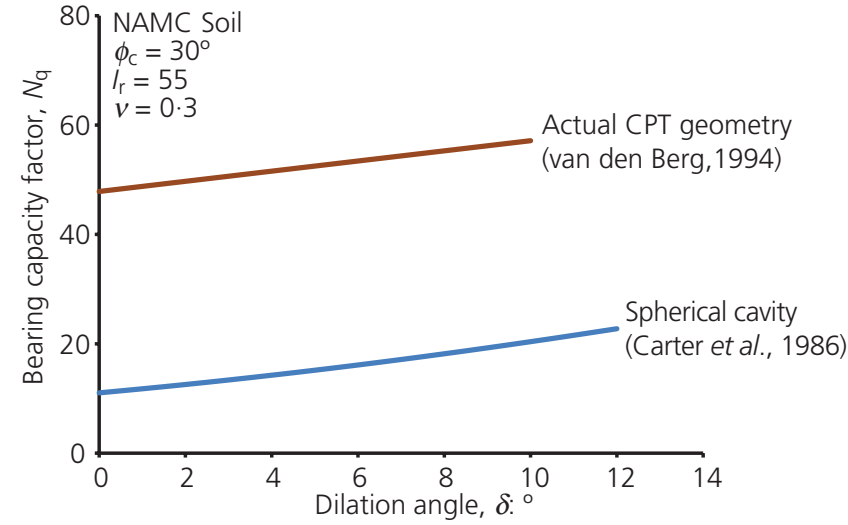

Figure 13. Scaling between CPT tip resistance from finite-element analysis and spherical cavity limit pressure in NAMC soil

\section{Cavity expansion with good soil models}

It is clear from calibration chamber studies that there is no unique relation between dilation and normalised CPT resistance Figure 14 illustrates some examples of trends found in calibration chamber studies, this figure showing test data on ten normally consolidated clean sands. Any particular sand follows Equation 12 , but there is a wide difference in the values for the coefficients $k$ and $m$ from one sand to another. The trends are not parallel, and there is about a factor of 4 between the lowest resistance and the greatest at any particular state. Figure 14 is presented in terms of the state parameter, but it makes no difference if the calibration data are presented in terms of dilation angle, void ratio or relative density: the large systematic differences continue to exist between the various sands used for CPT calibration. The bandwidth shown in Figure 14 is commonly attributed to 'compressibility' (e.g. Robertson and Campanella (1983)), although in reality this is too simple. Modelling is needed to understand how and why soil properties affect the mapping between CPT and soil state.

The initial attraction of the cavity expansion analogue was that it allowed closed-form solutions for Tresca, Mohr-Coulomb and

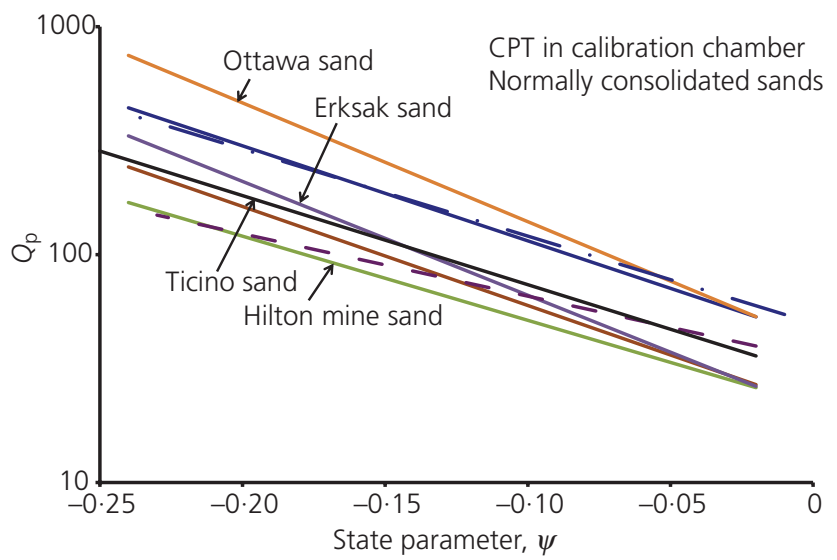

Figure 14. CPT resistance trends against state parameter for ten sands
NAMC soils. However, as finite-element simulations with real CPT geometry are so difficult, and with none having achieved realistic results for good soil models, it is attractive to return to cavity expansion and use a good model in that. Such cavity expansion studies require the scaling factor $C_{\mathrm{Q}}$ to be established by calibration to physical tests, but at least they offer insight on how the soil properties affect the CPT.

The first contribution using a good model was that of Collins et al. (1992), who adopted a CSL with the semi-log idealisation; strength varying with $\psi$ using the average trend of Been and Jefferies (1985); Bolton's (1986) stress dilatancy; and $G_{\max }$ that depended on mean stress and void ratio. The spherical cavity expansion was expressed as simultaneous differential equations with the solution computed using a standard numerical solver. The numerical results were approximated by

13. $Q_{\mathrm{p}}=c_{1} p^{\left(c_{2}+c_{3} v\right)} \exp \left(c_{4} v\right)$

where $v$ is the initial specific volume of the sand $\left(v=1+e_{0}\right)$ and $c_{1}$ to $c_{4}$ are coefficients that depend on the sand properties ( $\Gamma$ and $\lambda$ in particular). Collins et al. (1992) provided values of the coefficients $c_{1}$ to $c_{4}$ for several of the sands used in the various calibration chamber studies, including Reid Bedford, Ticino and Ottawa sands that capture the trend and bandwidth of these calibration studies (see Figure 14). Using the coefficients quoted by Collins et al. (1992), and the reported $e_{0}$ and $p_{0}^{\prime}$ for each result of a calibration chamber test on that sand in the database, gives a comparison of this spherical cavity solution with CPT calibrations for these three sands, which is shown in Figure 15.

There are two aspects of interest in Figure 15. First, the computed spherical cavity results are close to the measured CPT resistance at low values of $Q_{\mathrm{p}}$ - in essence, when the initial state of the soil is close to $\psi_{0} \approx 0$. But as the sand becomes denser, and thus more dilatant, the computed results systematically diverge from calibration measurements with the spherical cavity $Q_{\mathrm{p}}$ being a third of that measured for very dilatant states. Second, the offset between spherical cavity limit pressure and measured CPT resistance varies between the three sands shown with the most 'compressible' Reid Bedford having less offset than the least compressible Ottawa sand; the Ticino offset is intermediate between these two. The scaling factor inversely mirrors the trends shown in Figure 14.

A scale factor that varies with $Q_{\mathrm{p}}$ is not an overly concerning issue, as it merely adds little bit of complexity. However, the second observation of sand-specific scaling is more serious, as it leaves substantial uncertainty when moving to a different soil for which calibration chamber data do not exist - and avoiding that uncertainty is the whole purpose of the theoretical method.

It is a reasonable proposition that the work of Collins et al. (1992) was limited by their soil model rather than their approach to spherical cavity analysis. A particular concern is their NAMC-like 


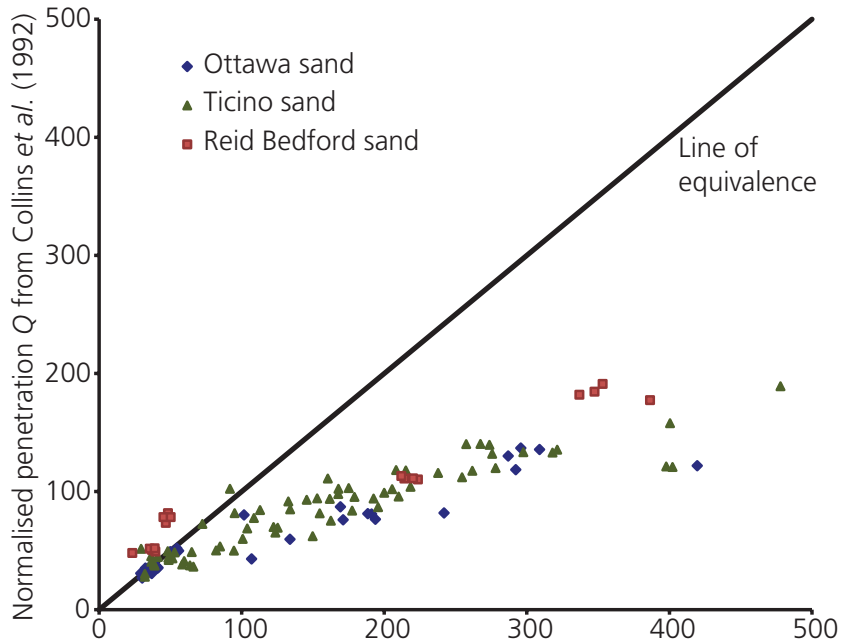

Normalised penetration resistance $Q$ measured in calibration chamber

Figure 15. Collins et al.'s (1992) spherical cavity limit pressure compared to CPT tip resistance in calibration chamber tests for three sands

assumption that yielding does not occur until the stress ratio $\eta$ reaches the value inferred from the Been and Jefferies (1985) trend; the stress-strain behaviour of sand in drained triaxial compression cannot be reasonably captured with such an assumption, even though the assumption is good enough for 'strength'. It is thought that this deficiency underlies the mismatch evident in Figure 15, as cavity expansion in an infinite medium is a very confined situation that magnifies the effect of volumetric strains induced during shear.

In short, the work of Collins et al. (1992) was an interesting first step but is not sufficient for practical engineering, where there is a need to compute CPT calibration from familiar soil properties.

\section{Spherical cavity expansion in NorSand}

The next substantive contribution was that of Shuttle and Jefferies (1998), who adopted the first variant of NorSand, a variant that captured the complete stress-strain behaviour across the spectrum of soil behaviour. Since then, NorSand has been modified in three ways: $(a)$ the soil property $\chi$ was introduced to reflect the effect of wider ranges of gradation and mineralogy on the maximum dilation shown by any soil; $(b)$ it was recognised that the soil property $N$ might be better viewed as affecting the scaling of the yield surface through an operating critical friction ratio $M_{\mathrm{i}}$ (analogous to $\phi_{\mathrm{f}}$ of Rowe (1962)) rather than being used to specify the shape of the yield surface; and $(c)$ the representation of $M_{\mathrm{i}}$ was changed to a computationally simple form (Jefferies and Shuttle, 2011). A further refinement has been elasticity.

The early version of NorSand followed the spirit of critical-state soil mechanics with the idea that elastic shear modulus should be expressed as a dimensionless elastic rigidity $I_{\mathrm{r}}-$ this is a 'clay-like' idealisation with the elastic modulus scaling with mean effective stress. But no sand behaves like this (see Figure 8). Thus, the power law dependence of $G$ on $p^{\prime}$ has been introduced together with an effect of void ratio: Equation 5. This elastic law improves accuracy, but does so by adding another two soil properties; the exponent of the power law and the lower limit of accessible void ratio $e_{\min }$. What follows uses this modified NorSand (as per the Appendix) in drained spherical cavity expansion, which is compared to the CPT calibration chamber data to establish the scaling factor, before moving on to consider undrained spherical expansion.

\section{Numerical method}

The finite-element method was used for the work reported here, with the numerical approach for spherical expansion being similar to that used by Shuttle and Jefferies (1998) for drained sand. The updated flow chart for the numerics is shown in Figure 16. In addition to the NorSand constitutive model, the Fortran program includes the NAMC model to allow verification of the finite displacement (a.k.a. large strain) component of the spherical cavity expansion implementation.

NorSand was implemented using an incremental viscoplastic formulation following the approach of Zienkiewicz and Cormeau (1974). This is computationally simple, but there is no theoretical maximum time step for numerical stability comparable to that derived for NAMC plasticity (Griffiths, 1980). The time step required for stability with NorSand is small, about one twentieth of the NAMC value and varying within the simulation as the elastic shear modulus varies. This small time step was not a particular constraint for the analyses considered here.

The spherical cavity expansion of NorSand simulations of Shuttle and Jefferies (1998) allowed the initial elastic shear modulus to vary as per the elastic idealisation, but within any simulation, that modulus was then constant. Here, that work is duplicated and then extended to use $G$ that varies throughout the domain of each simulation in accordance with the elastic idealisation.

Simulations of triaxial compression were used to verify the implementation of the NorSand constitutive model. The viscoplasticity component of the numerics was standard small strain, and the numerical approach of this triaxial code used the general approach of Smith and Griffiths (1988). A mesh of 16 (4 wide by 4 high) eightnode elements was used so as to identify any internal instabilities that might be hidden with a single element.

The simulations for spherical cavity expansion were more sophisticated and adopted the elements optimised for cavity expansion proposed by Yu (1990). Typically 70 elements were used, distributed logarithmically with radius so that there are more elements near the cavity where the strain gradients are greatest. The finite-displacement approach used was 'Lagrangian' with the finiteelement mesh being associated with material points - as strains develop, the mesh moves. A moving-mesh approach is near trivial to implement for the symmetric situation of cavity expansion and its associated kinematic constrains - it just requires radial coordinate updating at each step in the cavity expansion, which is a 


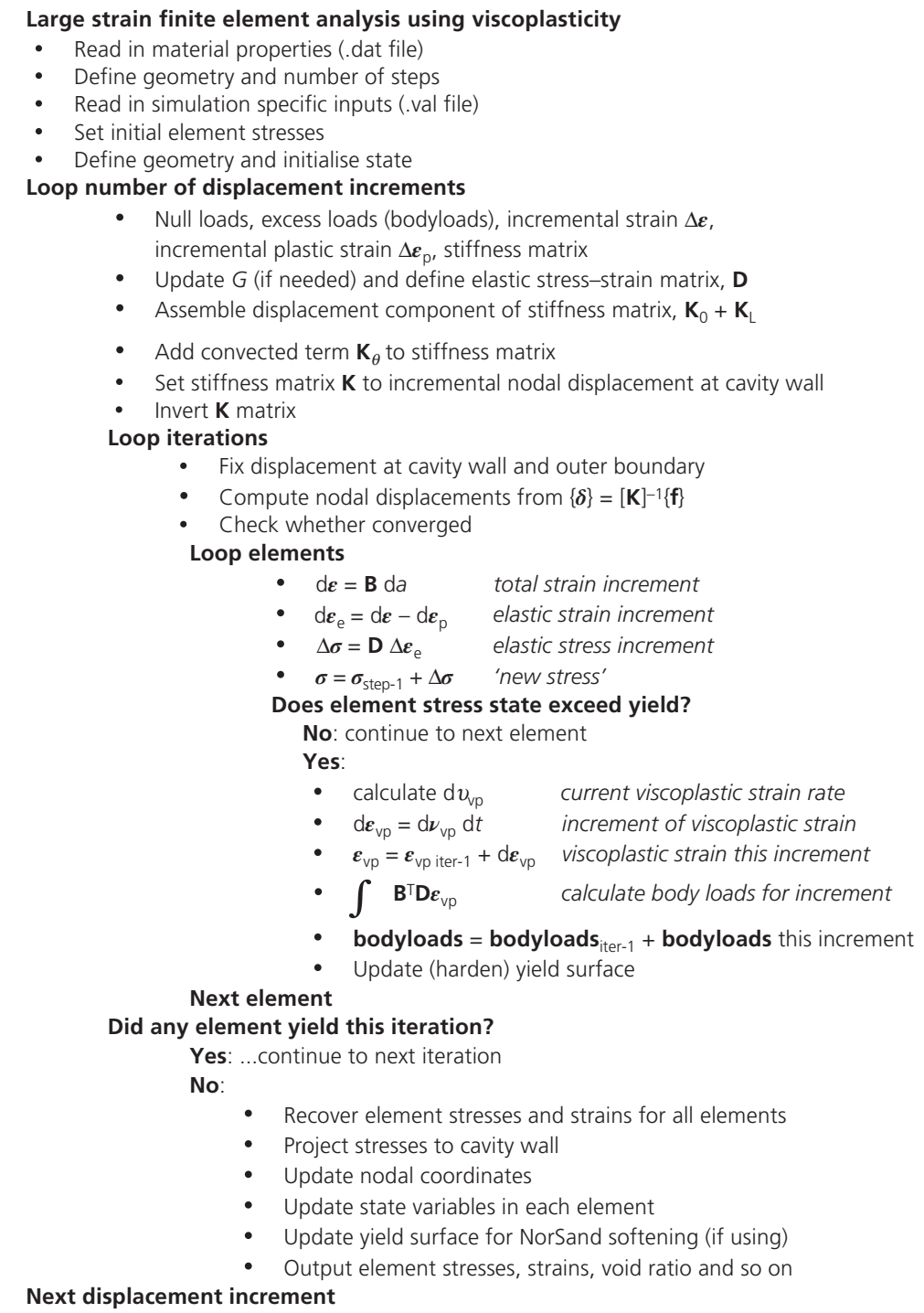

Figure 16. Flow chart of large-strain finite-element (FE) code for spherical cavity expansion

minimal overhead. What is less trivial is that moving the mesh convects work, and this convected work must be included in the solution; including convected work is further complicated by changing void ratio as the mesh moves because of dilation. The derivation of the additional term required for convected work is given by Shuttle and Jefferies (1998); the additional term used differs from that found in the paper of Zienkiewicz and Taylor (1991) because of allowing for void ratio change during mesh movement - a necessary improvement for dilating soil.

\section{Verification of numerics}

In the case of NorSand, verification of the viscoplasticity implementation have been reported for sands (Shuttle and Jefferies, 1998). The additional verifications carried out here check that the parameter combinations associated with silts do not cause some untoward behaviour, and also focus on undrained behaviour.
The reference solution for the verification is the direct Euler integration of NorSand that is implemented in the spreadsheet used for iterative forward modelling - denoted as 'VBA', as Visual Basic for Applications is the environment it is programmed in. Two examples of such verifications are shown in Figure 17, one for a lightly dilating silt and one for a very contractive silt (quite extreme parameter combinations are used, as the purpose in this instance is to test the numerical procedures, not to best-fit real silt). The finite-element and VBA integrations were very close, indeed indistinguishable, within the thickness of the plotted lines for the denser silt. No numerical instabilities were encountered.

Verification of spherical cavity expansion, including finite displacement, used a spherical NAMC formulation similar to that described by Shuttle and Jefferies (1998) so that the finite-element results could be directly compared to Carter et al.'s (1986) 

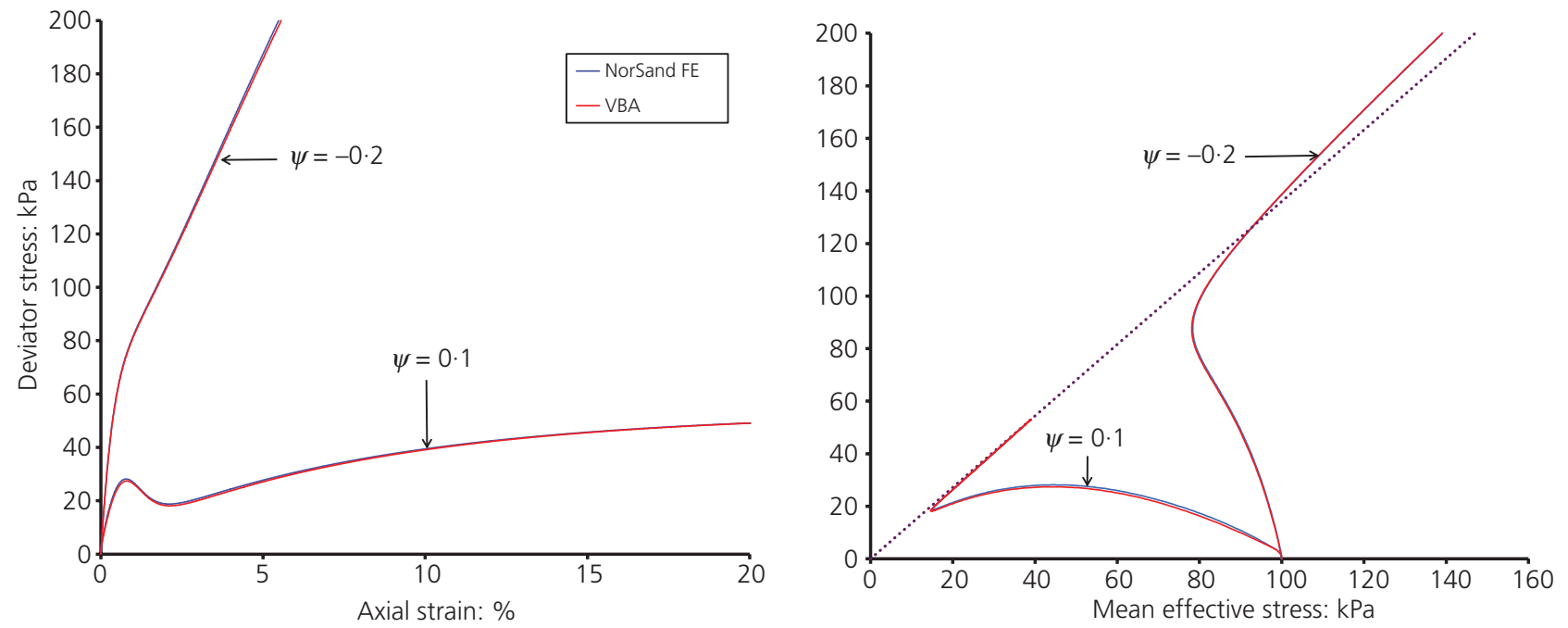

Figure 17. Verification of viscoplastic finite-element (FE) implementation of NorSand in undrained triaxial compression of silt

closed-form solution. Some comparisons are shown in Figure 18, one set for a stiff $I_{\mathrm{r}}=1000$ soil and another for a rather softer $I_{\mathrm{r}}=250$ soil. In the case of the stiff simulations, the finite-element and Carter
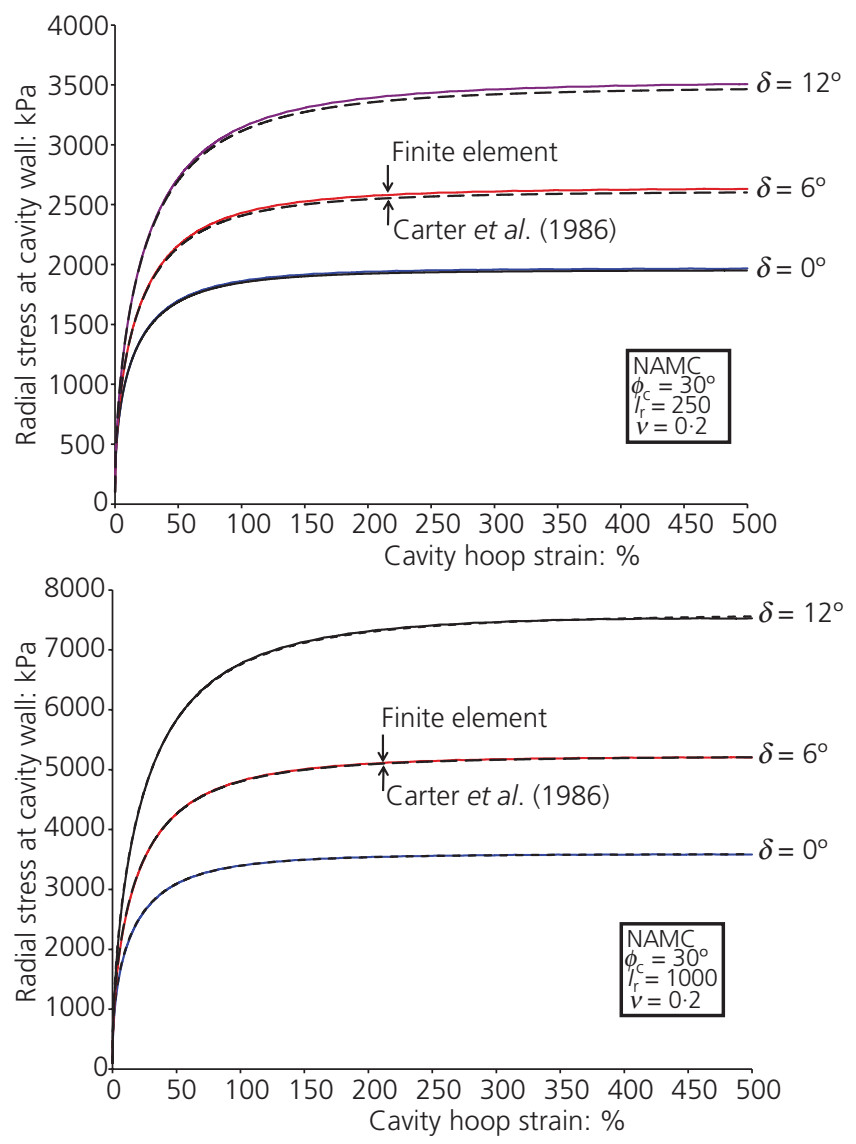

Figure 18. Verification of large-strain finite-element code for drained spherical cavity expansion in NAMC soil et al. (1986) solutions are virtually indistinguishable throughout the entire cavity expansion, including the limit pressure. In the case of the softer simulations, the two solutions diverge slightly.

\section{Drained calibration in sand}

Although this paper addresses the response of silt to the CPT, a difficulty in doing this is that there are no calibration chamber results in silt that can be used to develop the spherical-CPT mapping factor $C_{\mathrm{Q}}$. Hence, the approach adopted is to better understand this factor $C_{\mathrm{Q}}$ in sand and then assume that the developed understanding can be transported to silts since nothing in the mechanics changes; this assumption depends on relating $C_{\mathrm{Q}}$ to the soil properties.

Not all of the reported chamber test programmes are suitable for determining $C_{\mathrm{Q}}$ as some programmes have rather few tests - such programmes are useful checks, but in themselves contain insufficient information to define trends. Hence, this paper focuses on the data for Ottawa sand (the least compressible sand of the available data and with well-defined trends), Ticino sand (by far the largest data set) and Hilton Mine sand (by far the most compressible and with a trace of silt). Erksak sand is also considered, as this was in the largest chamber with the least boundary corrections. These tests span the range of reported calibrations (see Figure 14) and represent a range of properties, albeit those properties are skewed to the clean quartz sands of academia rather than the sands with some silt found in practical construction.

Each of the sands considered had a reasonable number of triaxial tests to define their properties (commonly four to five drained and three to five undrained). Table 2 presents the properties of these sands, and there is little 'wiggle room' with these values. For example, the properties $M$ and $N$ are determined using Bishop's procedure of plotting $\eta_{\max }$ against $D_{\min }$ with the properties defining the fitted trend line; increasing $M$ above its central value requires a 


\begin{tabular}{|c|c|c|c|c|}
\hline & Ottawa & Ticino & Erksak & Hilton Mine \\
\hline \multicolumn{5}{|c|}{ Particle size distribution } \\
\hline$D_{50}: \mu \mathrm{m}$ & 530 & 530 & 355 & 200 \\
\hline 'Fines': \% & 0 & 0 & $3 \cdot 0$ & $2 \cdot 5$ \\
\hline \multicolumn{5}{|c|}{ Critical state } \\
\hline$\Gamma$ & 0.754 & 0.985 & $0 \cdot 84$ & $1 \cdot 305$ \\
\hline$\lambda_{10}\left(\lambda_{\mathrm{e}}\right)$ & $0.028(0.012)$ & $0.055(0.024)$ & $0.050(0.022)$ & $0.160(0.070)$ \\
\hline$M_{\mathrm{tc}}$ & $1 \cdot 13$ & $1 \cdot 28$ & $1 \cdot 18$ & $1 \cdot 42$ \\
\hline \multicolumn{5}{|l|}{ Dilatancy } \\
\hline$N$ & $0 \cdot 25$ & $0 \cdot 34$ & $0 \cdot 20$ & $0 \cdot 35$ \\
\hline $\begin{array}{l}\chi_{\text {tc }} \\
\text { Plastic harc }\end{array}$ & $4 \cdot 70$ & $4 \cdot 00$ & $3 \cdot 40$ & $2 \cdot 70$ \\
\hline$H$ & $130-1400 \psi$ & $55-850 \psi$ & $100-1000 \psi$ & $40-200 \psi$ \\
\hline \multicolumn{5}{|l|}{ Elasticity } \\
\hline$A: \mathrm{MPa}$ & $9 \cdot 7$ & $9 \cdot 5$ & $9 \cdot 5$ & $4 \cdot 3$ \\
\hline$b$ & $0 \cdot 50$ & 0.47 & $0 \cdot 47$ & $0 \cdot 70$ \\
\hline$e_{\min }{ }^{a}$ & $0.30(0.49)$ & $0.35(0.58)$ & $0.35(0.53)$ & $0.50(0.62)$ \\
\hline$v$ & $0 \cdot 20$ & 0.20 & $0 \cdot 20$ & $0 \cdot 20$ \\
\hline
\end{tabular}

a The value of $e_{\min }$ was determined by regressing the fitted elastic model to minimise the deviation of data from the modelled trend. The value of $e_{\min }$ shown inside parentheses is that determined by the ASTM procedure

Table 2. Properties of sands used for calibration chamber tests

corresponding change to $N$ to fit the data set. Without formalising, a reasonable judgement is that $\lambda_{10}$ has a precision $\pm 0.002 ; M, \pm 0.02$; $N, \pm 0.03$ and $\chi, \pm 0.2$ for these chamber sand data sets. Further details on the gradational and other index properties of the various calibration chamber sands can be found in the paper by Been et al. (1987b).

The data file for each calibration chamber programme contains the reported initial void ratio and stress conditions of each test, as well as the 'steady' penetration resistance attained. The initial void ratio and confining stress data were used as the starting point for the numerical simulations, so that there was a spherical cavity limit pressure computed for each of the actual tests. Figure 19 shows an example set of results (for Ticino sand). The spherical cavity solution is offset from the reference chamber results, and that offset depends slightly on $\psi$.

When introducing the results of calibration testing earlier (Figure 14), it was noted that these data sets are affected by elastic rigidity, with the high-rigidity data lying to the top of the results and the lowrigidity data lying to the bottom. As the effect of $I_{\mathrm{r}}$ on $k$ and $m$ must be known when faced with inverting CPT data to recover $\psi$, it is helpful to include explicitly the rigidity effect in the scaling factor $C_{\mathrm{Q}}$. This is easily done using parametric simulations, varying $I_{\mathrm{r}}$ with the finite-element code and otherwise constant properties. Figure 20 plots the effect for the four calibration chamber sands considered within reasonable accuracy, simple trends are evident for both $k_{\mathrm{sph}}$ and $m_{\text {sph }}$ with $\log \left(I_{\mathrm{r}}\right)$. This effect of $I_{\mathrm{r}}$ on CPT resistance is the cause of the so-called stress level bias when expressing the results of calibration chamber tests in terms of $\psi$ (Shuttle and Jefferies, 1998).
In terms of the general trend for CPT behaviour in sand, the purpose of using cavity expansion analogues is to quantify the effect of intrinsic soil properties on CPT resistance. The hypothesis is that the effect of soil properties will be fully reflected in $k_{\mathrm{sph}}$ and $m_{\mathrm{sph}}$, with the scaling factor $C_{\mathrm{Q}}$ in Equation 7 being a consequence of the difference in deformation patterns between an actual CPT and the spherical analogue - and which logically requires that $C_{\mathrm{Q}}$ not depend on soil properties. This hypothesis was thoroughly examined, and confirmed, for nine sands by Ghafghazi and Shuttle (2008). Here, that earlier work is updated to reflect the introduction of stress-dependent elasticity within the spherical code and the further enhancements (and simplifications) of NorSand since that time. A further important difference is that Ghafghazi and Shuttle (2008) used geophysically determined $G_{\max }$, whereas in this paper $G=G_{\max } / 4$ is adopted across the cavity expansion simulations, both with drained sands and undrained silts, for consistency with the fitting of undrained silt behaviour presented earlier. Similarly to Equation 10 fitted to the chamber data, the finite-element results can be expressed as

14. $Q_{\mathrm{sph}}=k_{\mathrm{sph}} \exp \left(-m_{\mathrm{sph}} \psi\right)$

where

15a. $k_{\mathrm{sph}}=a_{\mathrm{k}}+b_{\mathrm{k}} \ln \left(I_{\mathrm{r}}\right)$

15b. $m_{\mathrm{sph}}=a_{\mathrm{m}}+b_{\mathrm{m}} \ln \left(I_{\mathrm{r}}\right)$ 


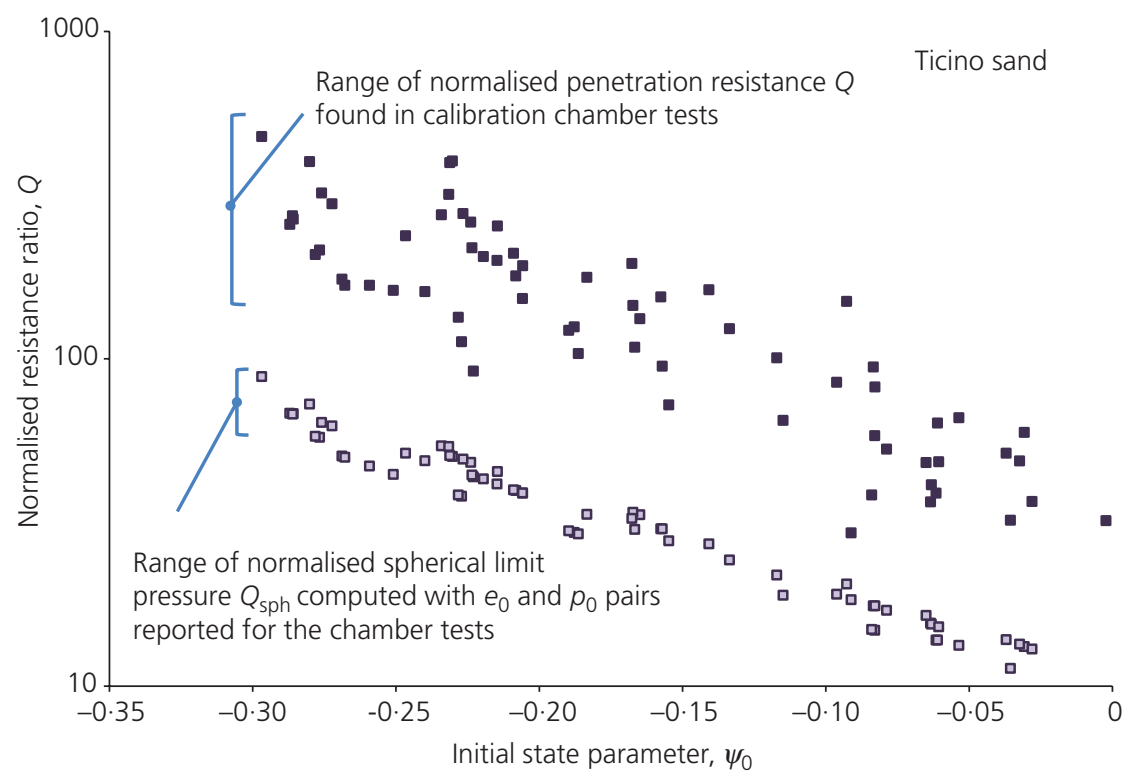

Figure 19. Comparison of numerical results for spherical cavity expansion in Ticino sand with data from calibration chamber tests

The coefficients $a_{\mathrm{k}}, b_{\mathrm{k}}, a_{\mathrm{m}}$ and $b_{\mathrm{m}}$ were determined by fitting trend lines through the results from parametric simulations shown in Figure 20; values of these coefficients for the four chamber sands considered are given in Table 3.

It is helpful for subsequent processing of CPT data in general (i.e. when applying the work to field data rather than calibration chambers) if $C_{\mathrm{Q}}$ is treated as comprising two components that reflect the offset and skewness between spherical and chamber that are evident in Figure 19. An appropriate form is

16. $C_{\mathrm{Q}}=c_{\mathrm{k}} \exp \left(-c_{\mathrm{m}} \psi\right)$

The purpose of the work is to best-estimate $\psi$. Accordingly, values of $c_{\mathrm{k}}$ and $c_{\mathrm{m}}$ were determined by minimising the difference between $\psi$ estimated using Equations 11 and 16 across the entire 130 results available for these four chamber programmes; strictly, Ticino is overrepresented in this minimisation as a soil type, but Ticino sand also includes a wide range of conditions that appear underrepresented with the other sands. The result of this optimisation was

17a. $c_{\mathrm{k}} \cong 3 \cdot 2$

17b. $\quad c_{\mathrm{m}} \cong 2 \cdot 4$

Figure 21 shows the match between $\psi$ computed from the reported $q_{\mathrm{c}}$ values and $\psi$ reported based on the test's initial void ratio and confining stress. The results lie around the line of equivalence, and the standard deviation of the difference between
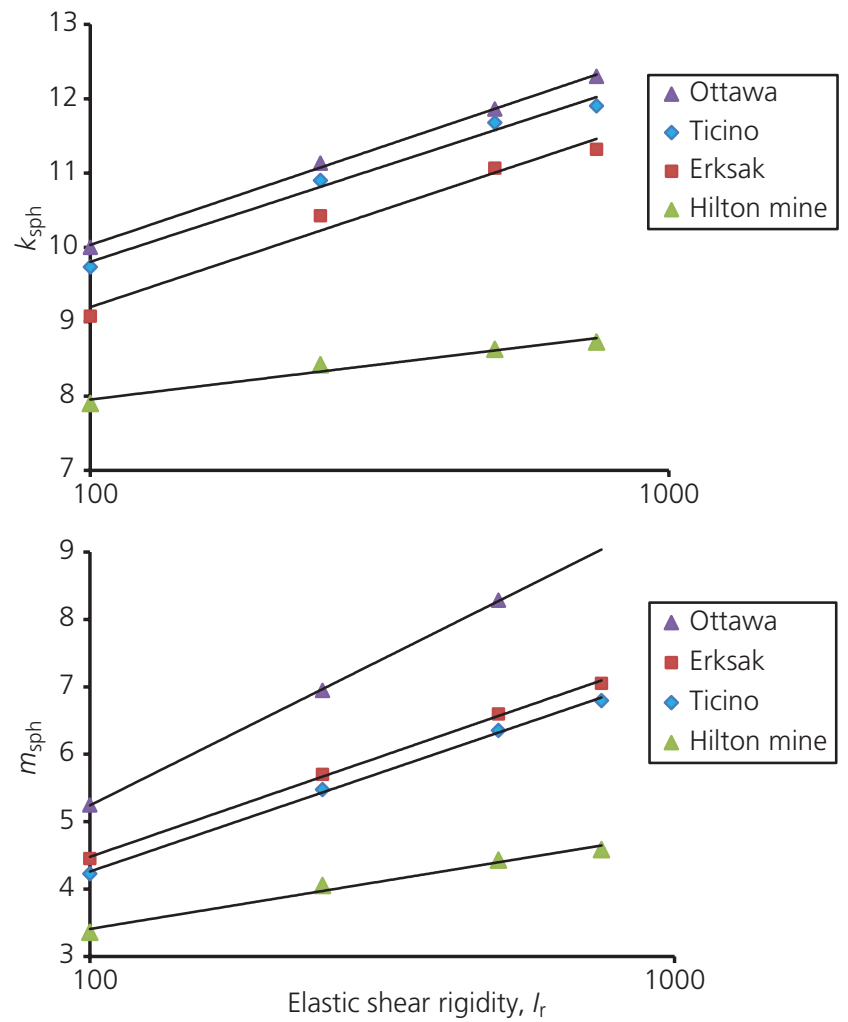

Figure 20. Effect of elastic rigidity $I_{r}$ on computed CPT coefficients $k_{\text {sph }}$ and $m_{\text {sph }}$

state computed from a test's reported $e_{0}$ and $p_{0}^{\prime}$ and that computed by the inversion from the reported $q_{\mathrm{t}}$ of that test is $\Delta \psi=0.02$ (lines have been drawn at two standard deviations from 


\begin{tabular}{lcccc}
\hline & $a_{\mathrm{k}}$ & $b_{\mathrm{k}}$ & $a_{\mathrm{m}}$ & $b_{\mathrm{m}}$ \\
\hline Ottawa & 4.650 & 1.004 & -2.658 & 1.728 \\
Ticino & 6.442 & 0.467 & -1.571 & 1.401 \\
Erksak & 5.110 & 0.797 & -1.292 & 1.276 \\
Hilton Mine & 6.092 & 0.344 & 0.881 & 0.571 \\
\hline
\end{tabular}

See Figure 19 for fit of trend lines to simulations

Table 3. Computed coefficients for spherical cavity expansion

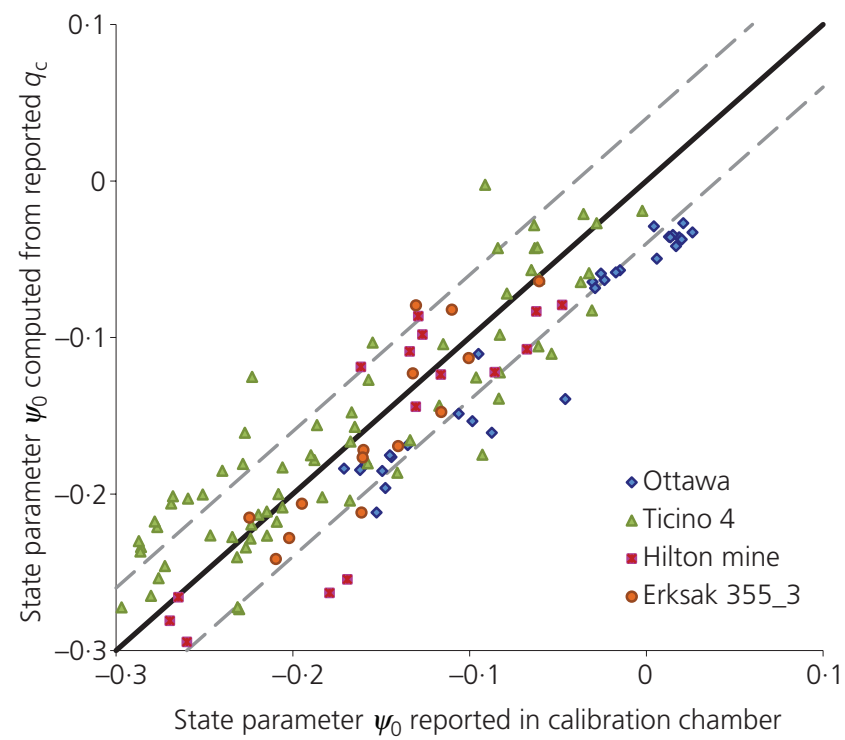

Figure 21. Accuracy in recovering $\psi$ from calibration chamber data (dashed lines show bandwidth $\psi \pm 0.04$ )

equivalence in Figure 21); most of this difference appears attributable to the intrinsic precision of chamber testing. Interestingly Hilton mine sand - the 'outlier' in most views of chamber testing - is now nicely captured and evenly distributed around the line of equivalence. Slightly less satisfactory is that while Ottawa sand is systematically biased more than one standard deviation from equivalence, equally, the Ottawa results are parallel to the computed trend and might be explained by a small error of $\Delta \Gamma \approx 0.03$ in the assessed CSL (even though every effort was made to test the same sands in triaxial as used in the chamber, the two sets of testing were sometimes years apart with all the possibility for gradational differences that implies). The optimised $C_{\mathrm{Q}}$ is consistent with van den Berg's (1994) results for the effect of correct CPT geometry discussed earlier.

It is possible to carry out parametric simulations for every soil property to determine the effect of each property on $k$ and $m-$ Shuttle and Jefferies (1998) followed this route. However, the finite-element code runs so quickly - and both approaches depend on measured (or otherwise known) soil properties - so not a great deal of convenience is gained from approximating parametric trends, and a little accuracy is lost. This paper, therefore, provides a downloadable source code as Supplementary Material on this journal's website for any reader to use in computing $k$ and $m$ for their soils (there is also a user manual explaining the input file and how to transfer output to a spreadsheet).

\section{Undrained results for silts}

Most generally, undrained behaviour arises from the inability of pore water to move on the timescale of the loading. In the case of triaxial tests, undrained conditions are simply a boundary condition that is imposed by closing a drainage valve. Neither situation can affect the soil's properties. In the case of finiteelement programs, the change from drained to undrained loading is achieved by the specified bulk modulus of the pore fluid - a very low pore-fluid modulus (typically zero) gives a drained response, while using the modulus of water gives an undrained situation. Thus, all the numerical formulation described, verified and validated for sands is directly used for undrained loading by a single change of pore fluid bulk modulus in the input parameters.

The calibration of NorSand for silt properties was presented earlier, with the values being shown in Table 1. Examples of the fit of NorSand to silt are shown in Figures 9 and 10. Simulations were run for a range of void ratio and confining stress (for ease of using the elastic idealisation) to define trends.

While the drained cavity expansion computes a limit pressure, undrained cavity expansion produces both this effective pressure and a matching excess pore pressure. When normalised by the initial conditions, these parameters correspond to the usual dimensionless groupings

18a. $Q_{\mathrm{p}}\left(1-B_{\mathrm{q}}\right)+1=\left(q_{\mathrm{t}}-u_{1}\right) / p_{0}^{\prime}$

18b. $B_{\mathrm{q}}=\left(u_{1}-u_{0}\right) /\left(q_{\mathrm{t}}-p_{0}\right)$

where $u_{1}$ is the excess pore pressure at the cavity wall or CPT tip. Figure 22 provides the scaled cavity expansion results in terms of these two parameter groups. The coefficients of the scaled cavity expansion in this silt (Silt_C in Figure 1 and Table 1) are $k=6 \cdot 2$ and $m=11 \cdot 7$.

Although it may seem remarkable, and unlike drained results in sand, the effective CPT resistance seen in Figure 22(a) is independent of elastic modulus with a unique relation between effective tip resistance and initial state parameter. This result is actually not remarkable at all because for undrained loading $\Delta e$ is effectively zero, and the soil at and near the cavity wall (or CPT) experiences very large shear strains and is corresponding in the critical state. And the critical state for undrained (= constant void ratio) shear of any soil is simply given by 
Determining silt state from CPTu

Shuttle and Jefferies
19. $\frac{p_{c}^{\prime}}{p_{0}^{\prime}}=\exp \left(\frac{-\psi_{0}}{\lambda_{\mathrm{e}}}\right)$

where Equation 19 follows from the definition of the state parameter. What is seen in Figure 22(a) is the expected consequence of the numerical procedures nicely and stably bringing the soil to its critical state and then continuing to deform it in that condition as the limiting cavity pressure develops. The soil properties $N, \chi, H$ and $G_{\max }$ have no effect in the critical state. Only $\lambda$ and $M$ matter.

Of course, this situation does not continue to $B_{\mathrm{q}}$, with the pore pressure reflecting both total stress change and the shear-induced excess pore pressure. All soil properties now matter. The computed $B_{\mathrm{q}}$ trends are shown in Figure 22(b). There is now an effect of elastic shear stiffness, with different trends for different rigidities.
The CPT is usually configured to measure pore pressure at the 'shoulder' of the probe (the $u_{2}$ location), as that has proved most useful in distinguishing between soil types. However, the cavity expansion analogue corresponds to conditions of displacement as well as shear - and that is at tip (the $u_{1}$ location). Penetrometers in engineering practice are equipped with a single pore pressure sensor, which is normally at the $u_{2}$ location, so the data of Peuchen et al. (2010) are used to map between the two pore pressures, as this mapping uses only the parameters measured by the CPT itself.

So far the CPT has been considered in terms of effective stresses. However, it is usual to evaluate CPT data on a total stress basis for undrained penetration of clays using

20. $s_{\mathrm{u}}=\frac{q_{\mathrm{t}}-\sigma_{\mathrm{v}}}{N_{\mathrm{KT}}}$

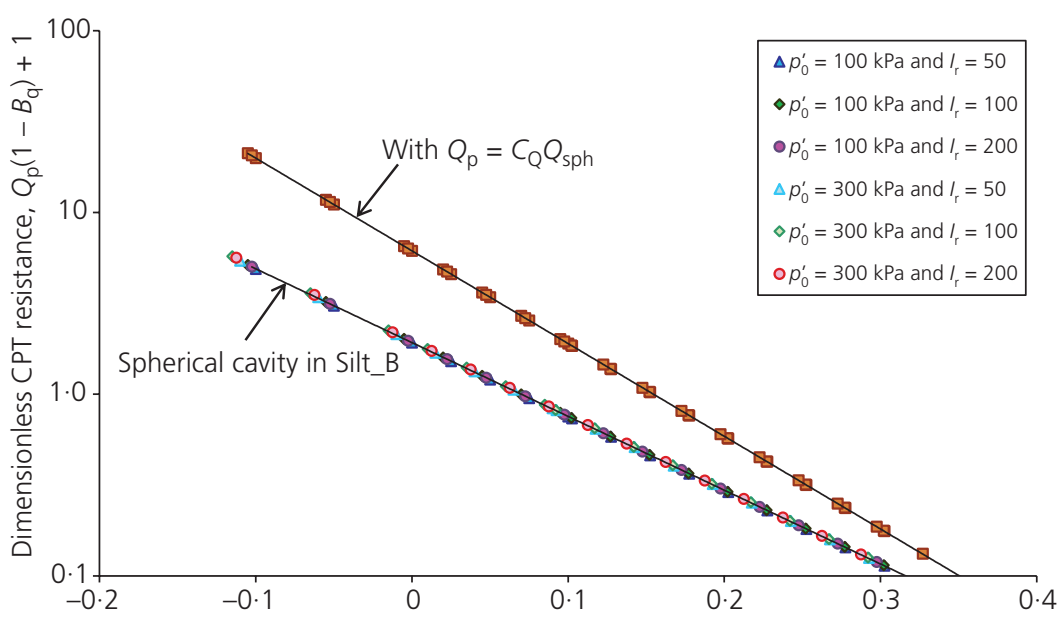

(a)

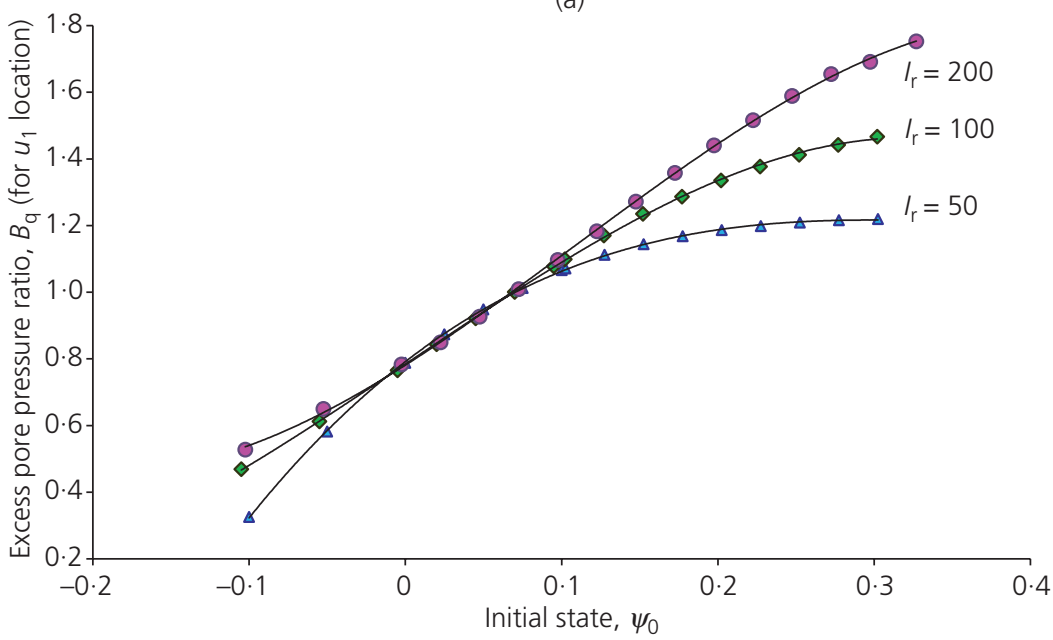

(b)

Figure 22. Numerical results for undrained spherical cavity expansion

in silt B. (a) Dimensionless CPT effective tip resistance $Q_{\mathrm{p}}\left(1-B_{\mathrm{q}}\right)+1$;

(b) excess pore pressure ratio $B_{\mathrm{q}}$ (at $u_{1}$ transducer location) 
where $N_{\mathrm{KT}}$ is the undrained cone factor (generally lying in the range of 11-20). As the peak undrained strength is available from simulations with NorSand for the chosen soil properties, it is straightforward to take the computed cavity expansion results previously presented separately in terms of effective stress and excess pore pressure to determine $N_{\mathrm{KT}}$. The computed $N_{\mathrm{KT}}$ factor is shown as a function of initial state parameter in Figure 23(a) for an elastic rigidity $I_{\mathrm{r}}=100$ (both the excess pore pressure induced by the CPT and the undrained strength vary with $I_{\mathrm{r}}$ as illustrated in Figures 10 and $22(\mathrm{~b}))$. In the case of lightly dilatant silt $\left(\psi_{0} \approx 0\right)$ with no softening, illustrated in Figure 23(b), $N_{\mathrm{KT}} \approx 13 \cdot 5$; as the silt becomes progressively looser, with brittle loss of strength after attaining $s_{\mathrm{u}}$, the $N_{\mathrm{KT}}$ factor increases and reaches $N_{\mathrm{KT}} \approx 16.5$ for the rather contractive silt $\left(\psi_{0} \approx+0 \cdot 2\right)$ that is also illustrated in Figure 23(b).

\section{Validation}

\section{Background}

Neves-Corvo is the largest mine in Portugal and the second largest copper mine in Europe, located near Castro Verde some $220 \mathrm{~km}$ south of Lisbon. Tailings from the mine are discharged into a 190 ha TSF, originally designed for subaqueous containment of the tailings using a rock fill dam across a natural river valley and supplemented by several smaller dams - the overall crest length of the dams is some $3.5 \mathrm{~km}$. The original tailing disposal capacity would have been exhausted in 2011, but the discovery of additional ore reserves extended the mine life. After consideration of alternatives, a change to stacked thickened tailings within the existing footprint was adopted - Lopes et al. (2013, 2015) described the basis for this change to tailing disposal. Stacking is planned currently at an overall slope of $\sim 5 \%$, achieved using berms that contain cells of thickened tailings. In practical terms, this change will have weak silts used as engineered fill stacked some $25 \mathrm{~m}$ above the perimeter dams and underlain by even weaker silts ('slimes' in the mining vernacular) as their foundation.

The engineering of this change to stacked tailings has been based on extensive CPT soundings to characterise the original subaqueous tailings (which include some sands as well as the predominant silts) and the new thickened tailings. The CPT soundings have been complemented by extensive laboratory testing on both reconstituted and undisturbed samples. The principal concern has been liquefaction failures, whether triggered by earthquakes or simply from static loading during construction (as happened in the recent Fundão tailing dam failure in Brazil).

\section{Site investigation data}

Silt tailings are weak soils and CPT transducers that comply with the usual standards EN ISO 22476-1 (ISO, 2012) or ASTM D 5778 (ASTM, 2012) are insufficiently accurate. The data discussed here were obtained with $0.5 \%$ at $10 \mathrm{MPa}$ tip sensors, with both the tip and pore pressure sensors calibrated on site by lowering the probe through a $20 \mathrm{~m}$ column of water (easily done in the thickening plant).

An example of the CPT data from a weaker part of the TSF is shown in Figure 24, this figure being annotated to highlight several aspects. First, tailings are new deposits that have been placed quite quickly - some may still be consolidating, while others may show underdrainage into original ground (fractured rock at Neves-Corvo); the current piezometric regime needs

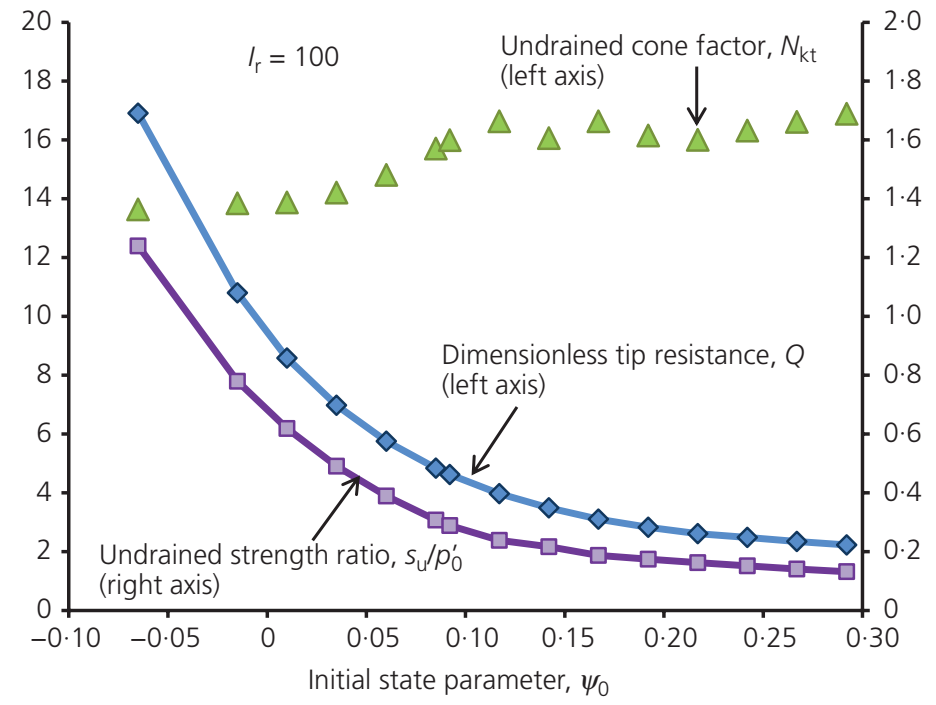

(a)

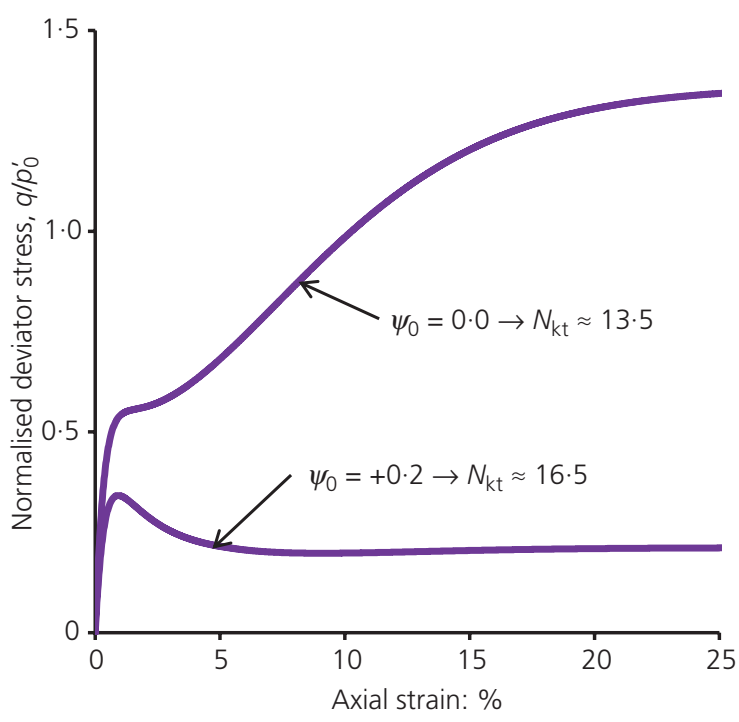

(b)
Figure 23. Computed $N_{K T}$ factor and associated silt stress-stain behaviour in silt B. (a) Variation of undrained cone factor $N_{\mathrm{kt}}$, tip resistance $Q$, and undrained shear strength ratio $s_{u} / p_{0}^{\prime}$ with initial state $\psi_{0}$; (b) examples of undrained stress-strain behaviour associated with computed $N_{\mathrm{kt}}$ values 


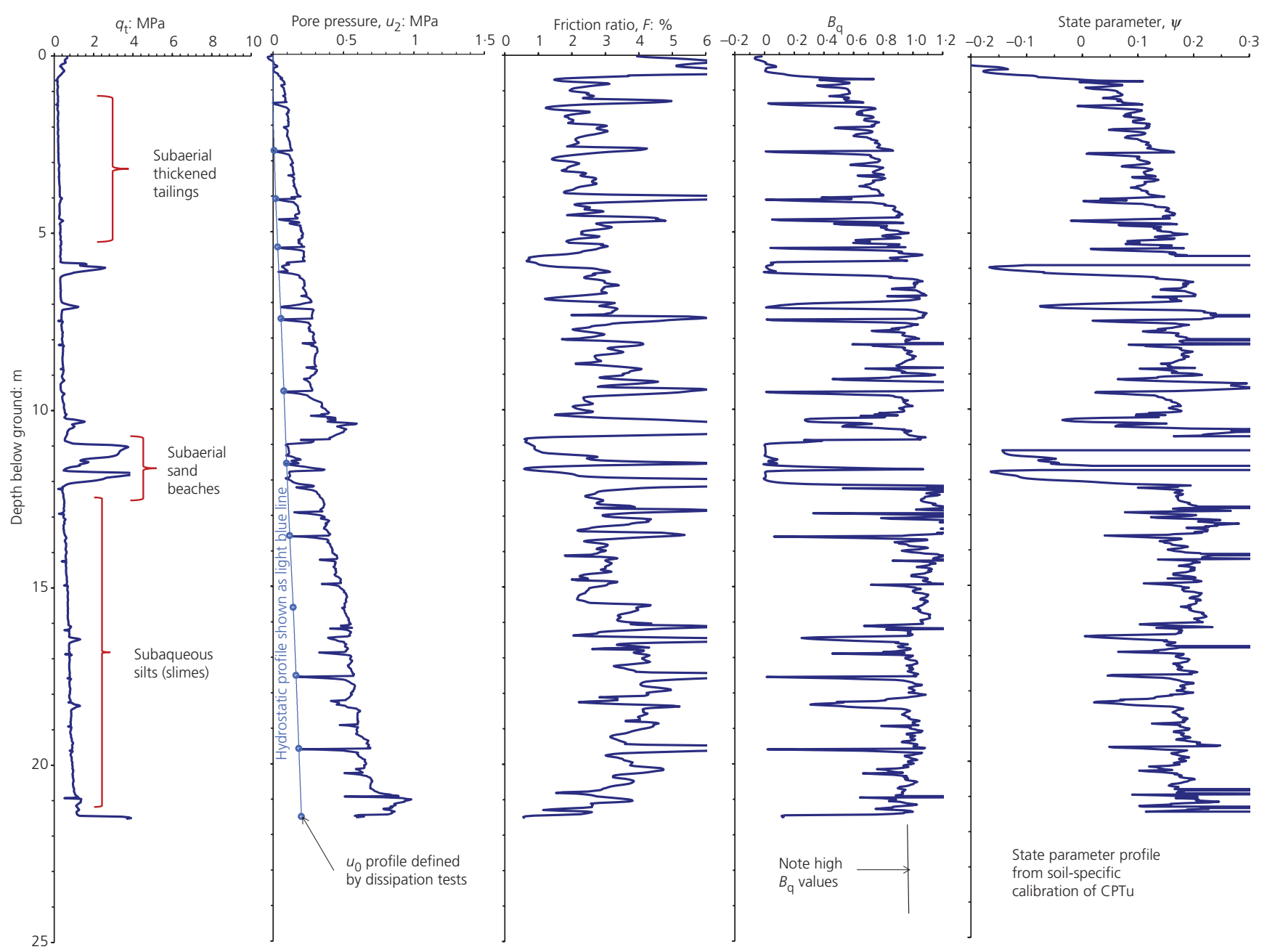

Figure 24. CPT profile in massive silt tailing deposit

determination at the time of CPT soundings, conveniently done by dissipation tests when adding pushrods, as at this site. Second, the weak consistency of these silts is evidenced by the high $B_{\mathrm{q}}$ values, which are noticeably larger than those found in most natural soft clays. Third, these $B_{\mathrm{q}}$ values fluctuate about the basic trend in both the thickened tailings and the subaqueous silts, indicating some vertical variation in state; in the case of the deeper silts, there may be an effect of changes in distance from the spigot point from year to year as the tailings accumulated, while the thickened tailings do not segregate but do experience variable drying during placement.

The CPT campaign was accompanied by undisturbed sampling, with careful logging of the water content of the as-recovered samples. Most of the undisturbed samples were in the subaqueous silts, and these sample locations were chosen to complement the understanding of site conditions from the CPT. The water content logging was on a 'whole-sampler' basis. Samples were carefully stored at their in situ orientation and protected from moisture loss until just prior to laboratory testing. Here interest is in strength data, and those data were obtained by computer-controlled triaxial equipment with careful determination of the as-sheared water content using the 'freezing method' at the end of each test.

An example of the measured behaviour of the undisturbed silt is shown in Figure 25. The sample is moderately dilatant. It is dilatant because it is denser than it is in situ, displaying the usual densification of silts during handling and reconsolidation that were discussed at the outset of this paper (see Figure 3). Correction of this densification to the stress-strain behaviour at in situ void ratio depends on properties determined on reconstituted samples.

\section{State determined from undisturbed samples}

The testing of undisturbed samples was accompanied by another series of tests on reconstituted samples using a single representative gradation (obtained by blending several samples together to give enough single-gradation soil for ten triaxial tests). 
The blended gradation was needed as soil properties can be determined only by using several triaxial tests on the same soil with varying initial void ratio and confining stress, as well as requiring both drained and undrained tests - work discussed earlier in the paper and which produced the soil properties given for Silt_C in Table 1.

The in situ state parameter can be computed from the void ratio of the undisturbed samples if the CSL is known. The problem, however, is that minor changes in soil gradation affect $\Gamma$, and there was quite some variation in gradation within the subaqueous silts. The approach adopted was to use iterative forward modelling of the undisturbed samples with the initial state parameter treated as a 'freedom' to best-fit the model to data. At this stage all soil properties were kept the same as determined for the representative blended sample of the remoulded tests. With a good fit achieved, the CSL property $\Gamma$ was then adjusted to align the modelled void ratio with the measured 'as-sheared' void ratio (this actually has minimal effect on the computed stress-strain behaviour). An example of the achieved fit is also shown in Figure 25. The onsite state of each undisturbed sample was then computed using the fitted $\Gamma$ for that sample, the $\lambda_{10}$ determined on the remoulded samples, the 'as-recovered' void ratio of that undisturbed sample (from the water content logging mentioned earlier) and the estimated mean effective stress in situ using $K_{0}=0 \cdot 7$. These estimates of the in situ state parameter are shown in Figure 26.

The in situ states cluster around $\psi_{0} \approx 0 \cdot 20$; by comparison, the classic idealisation of normally consolidated behaviour without brittleness (i.e. normally consolidated original Cam Clay) corresponds to $\psi_{0}=\lambda$. Thus, the in situ behaviour of all these silts is expected to be contractive with a potential post-peak strength loss of about $50 \%$.
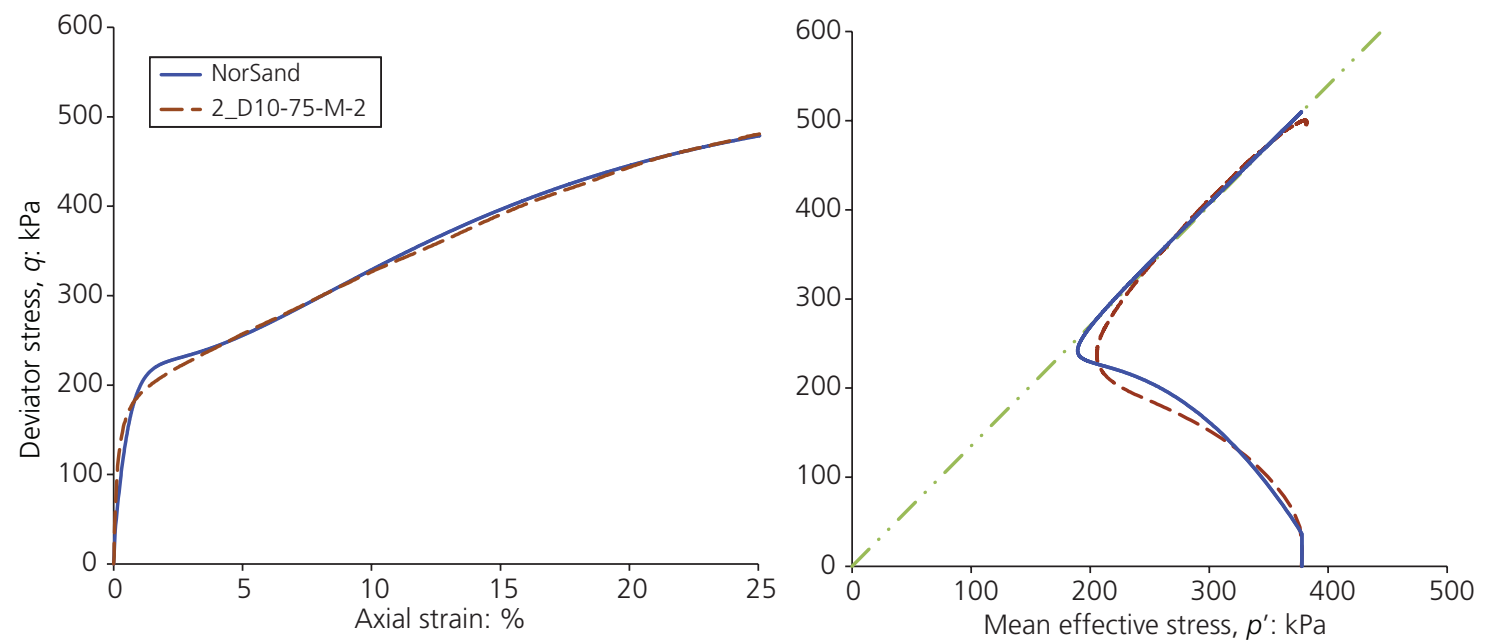

\section{State determination from CPT}

The results of three CPT soundings near these undisturbed samples have been processed into estimated in situ state parameters using the coefficients for this silt, $k=6.2$ and $m=11 \cdot 7$, which were computed earlier. The results of this data processing are also shown in Figure 26. Each plotted point corresponds to a nominal 25-mm depth increment of the CPT; there is considerable repeatability between the three $\mathrm{CPT}$ soundings.

\section{Validation}

Overall, the average state inferred from the CPT is broadly aligned with state inferred from the triaxial tests on the undisturbed samples, with the CPT data clustering close to the central estimate from the undisturbed samples.

The variability seen in the undisturbed samples appears much larger than indicated by the CPT data in the in situ silts. Regardless of the $\mathrm{C}_{\mathrm{Q}}$ factor, the $\mathrm{CPT}$ indicates quite uniform $B_{\mathrm{q}}, F$ and $q_{\mathrm{t}}$ trends - there is some variability in these soils in situ, but nothing like the range suggested by the undisturbed tests. In terms of the undisturbed tests, there is little wiggle room in the state parameter inferred from modelling their as-tested behaviour (see the fit in Figure 25), and their tested void ratio is reasonably precise (determined by the freezing method). Where there is considerable uncertainty is the as-recovered void ratio - this void ratio was determined from the measurements on the whole $0.8 \mathrm{~m}$ long sampling tube, which necessarily averages what the sampler contains. And it is the difference between the as-tested and asrecovered void ratios that give the inferred in situ state.

It is also true, however, that the silt does vary in gradation both laterally and vertically, whereas the data processing used coefficients for a single soil. If the effect of gradation change
Figure 25. Comparison of NorSand to undrained triaxial compression of undisturbed silt using properties from remoulded tests 


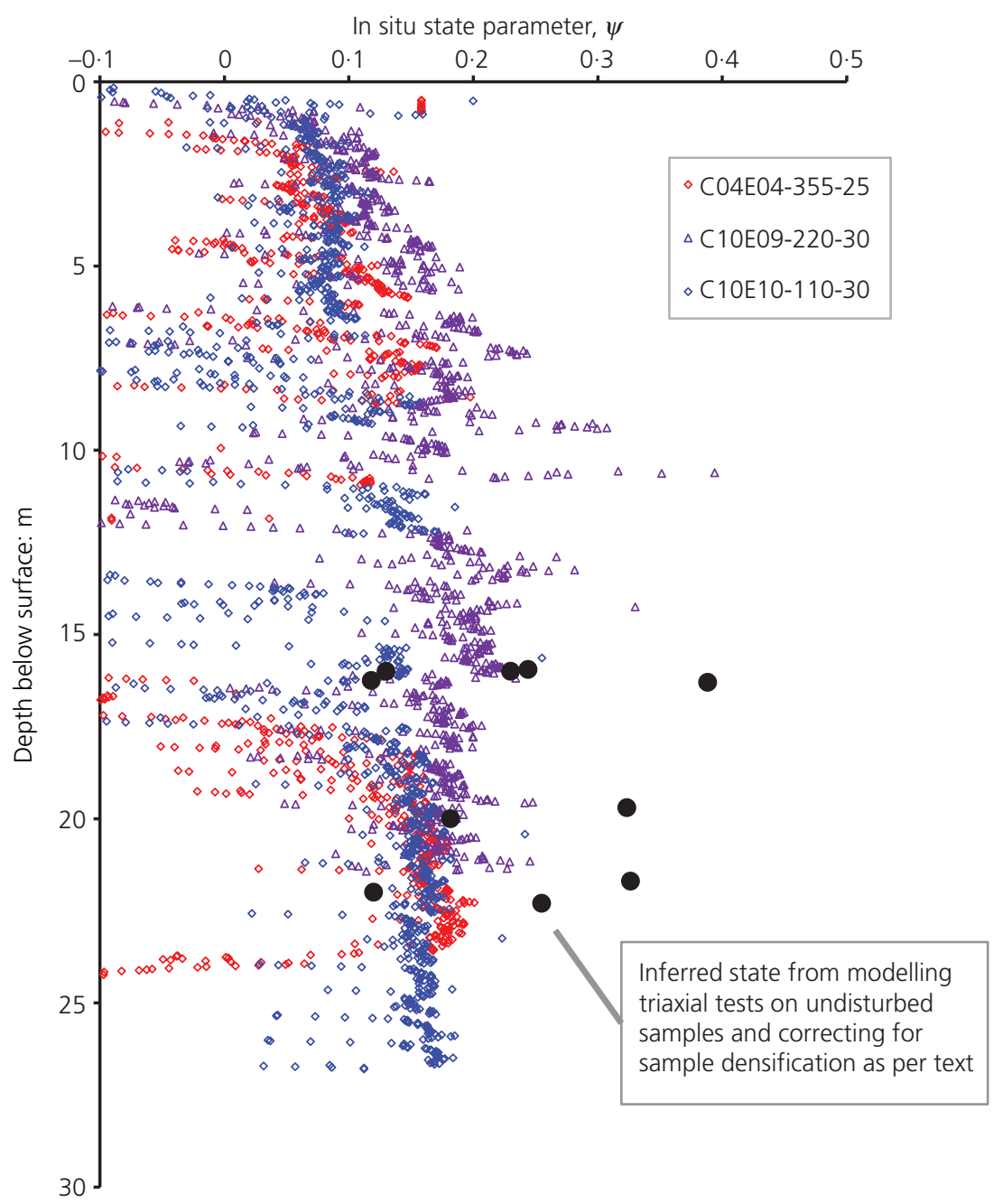

Figure 26. Comparison of silt state computed from CPT to silt state inferred from 'undisturbed' samples corrected for densification

predominantly affects $\Gamma$, that use of a single calibration will be reasonable as $\Gamma$ has minimal effect on the stress-strain behaviour that underlies the CPT calibration; equally, the variation seen in the measured friction ratio (Figure 24) indicates that $\lambda$ may vary a little as $\lambda$ often correlates to $F$ (Plewes et al., 1992; Reid, 2014). If $\lambda$ varies, then $k$ and $m$ may vary a little too. Allowing for such variation may attenuate some of the variability in the estimate of $\psi_{0}$, as there is a geologic tendency for the state to relate to depositional conditions across a spectrum of soil gradations (Jefferies and Been, 2015).

The CPT procedures themselves provide a second check on the estimated in situ state. Within these deeper silts, and neglecting the more dilatant 'spikes' as sandier interlayers, the range for the excess pore pressure ratio is $0.95<B_{\mathrm{q}}<1.15$ (see Figure 24); after applying the relation proposed by Peuchen et al. (2010) to map the data at the $u_{2}$ sensor used to a $u_{1}$ location, one finds $1 \cdot 20$ $<B_{\mathrm{q}}<1 \cdot 30$. The shear modulus data for the deeper silts is shown in Figure 8 and corresponds to $I_{\mathrm{r}} \approx 90$. Looking at Figure 22(b), an in situ state of $\psi_{0} \approx 0 \cdot 2$ at $I_{\mathrm{r}} \approx 90$ gives $B_{\mathrm{q}} \approx 1 \cdot 3$.

Overall, these validation considerations suggest using $C_{\mathrm{Q}}$ from drained calibration studies in sand because the effective-stress component of undrained spherical cavity expansion in silt is broadly consistent; there may be a slight bias, however, in that the predicted in situ state of the loose silt that is about $\Delta \psi \approx 0.02$ denser than is actually the case (assessed from visually shifting the processed CPT results to best align them to the undisturbed tests in Figure 24).

\section{Downloads}

Numerical studies such as those presented in this paper can be very time consuming for readers to implement. Accordingly, we have provided $(a)$ a commented Fortran source code for the spherical finite-element analysis; $(b)$ a 'user manual' on how to run the code and import results into Excel to derive CPT coefficients; and (c) the forward modelling environment for 
calibrating soil properties as an Excel application with commented source code in VBA.

The routine NorTxl in the VBA source code is easily viewed from Excel, and this commented code may be a better explanation of NorSand than the equations in the Appendix. It is also useful to quickly run a few simulations, as that will give a far better sense of what is captured by the model than what can be appreciated from figures in the written paper; some data files are included to assist (and the calibrations are documented).

The Fortran source code follows the general coding principles expounded by Smith and Griffiths (1988). Many users may be happy to simply compile the code and run it, but it was thought essential to fully expose the numerical method - there are no hidden factors.

These codes allow any reader to duplicate the results presented here either using the authors' data or their own. The downloads are on the journal's website as supplementary material - please do download and look at them as they are a part of the paper. All programs and data are subject to the GNU General Public License Version 2, in essence a use-at-own-risk license that encourages further developments based on that free software ('take it and run with it ...').

Much of the other laboratory and calibration chamber data used in this study are public domain (Jefferies and Been, 2015).

\section{Concluding remarks}

The practical importance of the bandwidth of the CPT calibration data, as illustrated in Figure 14, is poorly appreciated. Consider a CPT sounding in a sand which produced a measured normalised penetration resistance of $Q_{\mathrm{p}}=70$. If a calibration trend is adopted at the low side of the bandwidth, the inferred state is $\psi \approx-0 \cdot 14$, a state that will correspond to a very acceptable soil behaviour under most loadings, with substantial dilation and so forth. Liquefaction will not be a serious concern for such dense soil. Conversely, if the calibration trend adopted is at the high side of the bandwidth the inferred state is $\psi \approx-0.04$ for exactly the same penetration resistance $Q_{\mathrm{p}}=70$, such a state is vulnerable to liquefaction (static and/or cyclic) as, for example, as occurred in the recent billion-dollar failure at Fundão dam (Brazil). The entire engineering can depend on the CPT calibration used - 'high' or 'low' trend - not the measured CPT resistance $\left(Q_{\mathrm{p}}=70\right.$ in this instance). How should the calibration be chosen? And the situation becomes more troublesome when dealing with silts, as there are no reference calibration studies in silts at all.

The work of Been et al. (1987b) was a milestone, as it was the first to offer an approach to interpolating between existing calibrations for any particular sand. Strictly what was offered was a plausible basis for viewing test data using general principles of critical-state soil mechanics. The formal mechanics were subsequently provided by Shuttle and Jefferies (1998) and broadly supported by Been et al.'s (1987b) work while adding some refinement and insight. Subsequently, Ghafghazi and Shuttle
(2008) confirmed the universality of scaling the spherical cavity analogue to reference chamber data in sands. This paper builds on these computationally driven developments to consider undrained $\mathrm{CPTu}$ soundings, as required for silts, and with further reflection of scaling factors from Shuttle and Cunning (2007).

The derived relation for determining the state parameter from CPT data in silts, based on scaled undrained spherical cavity expansion, validates nicely at the example site with deep deposits of young silts ( $<25$ years old). The methodology is general, and calibrations can be computed for other soils provided that their properties are measured. But a limitation in this study has been the adequacy of the calibration chamber data, as these data are depended on to establish the 'cone factor' $C_{\mathrm{Q}}$ relating the results of the spherical cavity analogue to the CPT. As noted earlier, such calibration chamber data are seen as the gold standard but it is nothing like as accurate as commonly perceived. The lack of $G_{\max }$ data has been mentioned, which is to some extent a consequence of much of the chamber testing predating bender elements. Even Ticino sand, with its extensive $G_{\max }$ data, actually relied on a second study using the same sand. And in the case of Ticino sand data, there is an instance of two tests with the same $e_{0}$ and $p_{0}$ and yet a factor of 2 difference in the stable $q_{\mathrm{t}}$ value is reported - this is not to criticise the data themselves, but simply highlights the experimental difficulty in conducting these chamber calibrations and why a fair bit of scatter is found in the results of any calibration programme, hence the use of the calibration chamber data to scale computational trends anchored in mechanics and a preference for simple, plausible mathematical form rather than treating calibration chamber data as 'absolute facts' that must be matched. However, it must be acknowledged that the spherical cavity expansion is not as close an analogue to the CPT as desirable.

One obvious missing factor in the spherical cavity analogue is the load from the CPT shaft. In sands, this shaft load is on the order of $10 \%$ of the tip load (the friction sleeve is 15 times larger than the tip area, and $F \approx 0.5 \%$ is common) increasing to perhaps $30 \%$ of the tip load in silts with their greater $F$ values. And that does not include shaft friction loads from further behind the sleeve. Quite how this neglected load (within the spherical cavity analogue) becomes distributed away from an actual CPT is an interesting question, and it is certainly a plausible cause for $C_{\mathrm{Q}} \approx 4$ rather than $C_{\mathrm{Q}} \approx 2$.

Despite the precision of the numerics offered (see the verification plots in Figures 17 and 18), and the very reasonable matches of NorSand to soil behaviour of interest (e.g. Figures 9 and 25), these numerics are for the spherical cavity analogue, not the CPT itself. Many practical engineers will still prefer a physical calibration, as there may be a $C_{\mathrm{Q}}$ anxiety. Indeed, it is a little surprising that one sees so few calibration chamber studies in the context of billiondollar liabilities for many projects - surely some calibration tests might have been useful at Fundão? Lower-cost physical calibrations have been achieved by doing CPTu tests in a centrifuge (Bolton et al., 1999), with the advantage of a smaller sample and the fact that each test covers a range of effective stresses at the same void ratio. Scaling of the soil particle size to the CPTu diameter is a 
complication with sands, and it is typical to check the five or so centrifuge tests with a couple of full-scale calibration chamber tests. Other researchers are investigating whether an even smaller CPTu test in a triaxial specimen with good control of boundary stresses might be an alternative, but this is a relatively recent development (Damavandi-Monfared and Sadrekarimi, 2015).

Part of the reason that engineers are forced to look to calibration chamber studies is that the flow of soil past a CPT is a very difficult computational problem with variable dilation - it is unclear what streamlines might look like in variably dilating soils. But the research funding has never been there for this level of computational soil mechanics - which is disappointing when the worldwide extent of CPT testing is considered, and even more disappointing when the billion-dollar liabilities of some constructed works based on CPT data are considered.

Overall, it is suggested that engineers reflect on this truth: the CPT is the most repeatable, operator-independent and accurate test (given appropriate transducer choice) of all geotechnical tests - surely the CPT deserves the effort to understand this test so that the derived soil parameters are as accurate as the measured data? This paper has pushed the spherical cavity expansion analogue a little more, but really the industry needs more calibration studies, including in silts, and a much more advanced finite-element analysis.

\section{Acknowledgements}

The Neves-Corvo mine has been operated since 1988 by Sociedade Mineira de Neves-Corvo (Somincor), a subsidiary of Lundin Mining, with geotechnical aspects being the responsibility of Dr M. Oliveira.

The in situ and laboratory work for Somincor was carried out by Golder Associates (Portugal). Eng R Bahia directed this work, with substantial contributions from Dr N. Raposo and Dr R. Olivera, PEng.

The authors appreciated the opportunity to contribute to this most interesting mine development.

\section{Appendix}

\section{Internal model variables}

Critical state

Yield surface and internal cap $\left(\bar{\sigma}_{\mathrm{m} i}=\bar{\sigma}_{\mathrm{mx}}\right)$

Hardening rule

Flow rule

Elasticity

$$
\begin{aligned}
& \psi_{i}=\psi+\lambda \ln \left(\bar{\sigma}_{\mathrm{mi} i} / \bar{\sigma}_{\mathrm{m}}\right) \text { and } M_{i}=M\left(1-N \chi_{i}\left|\psi_{i}\right| / M_{\mathrm{tc}}\right) \\
& e_{\mathrm{c}}=\Gamma-\lambda \ln \left(\bar{\sigma}_{\mathrm{m}}\right) \text { and } \eta_{\mathrm{c}}=M=M_{\mathrm{tc}}-\frac{M_{\mathrm{tc}}^{2}}{3+M_{\mathrm{tc}}} \cos \left(\frac{3 \theta}{2}+\frac{\pi}{4}\right) \\
& \frac{\eta}{M_{i}}=1-\ln \left(\frac{\bar{\sigma}_{\mathrm{m}}}{\bar{\sigma}_{\mathrm{mi}}}\right) \text { with }\left(\frac{\bar{\sigma}_{\mathrm{mx}}}{\bar{\sigma}_{\mathrm{m}}}\right)=\exp \left(-\chi_{\mathrm{tc}} \psi_{i} / M_{i, \mathrm{tc}}\right)
\end{aligned}
$$

On outer yield surface

$\frac{\dot{\bar{\sigma}}_{\mathrm{m} i}}{\overline{\bar{\sigma}}_{\mathrm{mi}}}=H \frac{M_{i}}{M_{i, \mathrm{tc}}}\left(\frac{\bar{\sigma}_{\mathrm{m}}}{\bar{\sigma}_{\mathrm{mi}}}\right)^{2}\left(\frac{\bar{\sigma}_{\mathrm{mx}}}{\bar{\sigma}_{\mathrm{m}}}-\frac{\bar{\sigma}_{\mathrm{m} i}}{\bar{\sigma}_{\mathrm{m}}}\right) \dot{\varepsilon}_{\mathrm{q}}^{\mathrm{p}}+S \frac{\eta}{\eta_{\mathrm{L}}} \frac{\dot{\bar{\sigma}}_{\mathrm{m} x}}{\bar{\sigma}_{\mathrm{mx}}}$

where $S=0$ or 1 (a Boolean switch) and $\eta_{\mathrm{L}}=M_{i}\left(1-\chi_{i} \psi_{i} / M_{i, \mathrm{tc}}\right)$

On internal cap

$$
\frac{\dot{\bar{\sigma}}_{\mathrm{mi}}}{\overline{\bar{\sigma}}_{\mathrm{mi}}}=-\frac{H}{2} \frac{M_{i}}{M_{i, \mathrm{tc}}}\left|\dot{\varepsilon}_{\mathrm{q}}^{\mathrm{p}}\right|
$$

Stress dilatancy: $D^{\mathrm{p}}=M_{i}-\eta$

$D_{\mathrm{tc}}^{\mathrm{p}}=D^{\mathrm{p}} M_{i, \mathrm{tc}} / M_{i}$ and $D_{\mathrm{te}}^{\mathrm{p}}=D^{\mathrm{p}} M_{i, \mathrm{te}} / M_{i}$

$z_{3, \mathrm{tc}}=\frac{2 D_{\mathrm{tc}}^{\mathrm{p}}-3}{6+2 D_{\mathrm{tc}}^{\mathrm{p}}}$ and $z_{3, \mathrm{te}}=\frac{2 D_{\mathrm{te}}^{\mathrm{p}}-6}{3+2 D_{\mathrm{te}}^{\mathrm{p}}}$

$a=(\sin \theta+\sqrt{3} \cos \theta) / 3, b=-2 \sin \theta / 3, c=(\sin \theta-\sqrt{3} \cos \theta) / 3$

Strain rate ratios consistent with idealised work dissipation postulate

$$
\begin{aligned}
& \frac{\dot{\varepsilon}_{3}^{\mathrm{p}}}{\dot{\varepsilon}_{1}^{\mathrm{p}}}=z_{3}=z_{3, \mathrm{tc}}-\left(z_{3, \mathrm{tc}}-z_{3, \mathrm{te}}\right) \cos \left(\frac{3 \theta+90}{2}\right) \\
& \frac{\dot{\varepsilon}_{2}^{\mathrm{p}}}{\dot{\varepsilon}_{1}^{\mathrm{p}}}=z_{2}=\frac{a D^{\mathrm{p}}-1+\left(\dot{\varepsilon}_{3} / \dot{\varepsilon}_{1}\right)\left(c D^{\mathrm{p}}-1\right)}{1-b D^{\mathrm{p}}}
\end{aligned}
$$

$I_{\mathrm{r}}=\frac{G}{\bar{\sigma}_{\mathrm{m}}}$ with $K=\frac{2(1+v)}{3(1-2 v)} G, v=$ constant at all times 


\section{REFERENCES}

Alonso EE and Gens A (2006) Aznacóllar dam failure. Part 1: field observations and material properties. Géotechnique 56(3): 165-183, http://dx.doi.org/10.1680/geot.2006.56.3.165.

ASTM (2012) D 5778-12: Standard test method for performing electronic friction cone and piezocone penetration testing of soil. ASTM International, West Conshohocken, PA, USA.

Baligh MM (1985) Strain path method. Journal of Geotechnical Engineering 111(9): 1108-1136.

Becker DE, Jefferies MG, Crooks JHA and Been K (2006) Geology, characterization and properties of Beaufort Sea clays. Proceedings of the Second International Workshop Characterization and Engineering Properties of Natural Soils, Singapore, pp. 1855-1891.

Been K and Jefferies MG (1985) A state parameter for sands. Géotechnique 35(2): 99-112, http://dx.doi.org/10.1680/geot. 1985.35.2.99.

Been K, Crooks JHA, Becker DE and Jefferies MG (1986) The cone penetration test in sands: part 1, state parameter interpretation. Géotechnique 36(2): 239-249, http://dx.doi.org/ 10.1680/geot.1986.36.2.239.

Been K, Lingnau BE, Crooks, JHA and Leach B (1987a) Cone penetration test calibration for Erksak (Beaufort Sea) sand. Canadian Geotechnical Journal 24(4): 601-610.

Been K, Jefferies MG, Crooks JHA and Rothenberg L (1987b) The cone penetration test in sands: part II, general inference of state. Géotechnique 37(3): 285-299, http://dx.doi.org/10.1680/ geot.1987.37.3.285.

Bellotti R, Jamiolkowski M, Lo Presti DCF and O'Neill DA (1996) Anisotropy of small strain stiffness in Ticino Sand. Géotechnique 46(1): 115-131, http://dx.doi.org/10.1680/geot.1996.46.1.115.

Bishop AW (1950) Reply to discussion on 'Measurement of shear strength of soils'. Géotechnique 2(2): 90-108.

Bishop AW (1973) The stability of tips and spoil heaps. Quarterly Journal of Engineering Geology 6(3-4): 335-376.

Bishop RF, Hill R and Mott NF (1945) Theory of indentation and hardness tests. Proceedings of the Physical Society 57(3): 147-159.

Boliden (2016) http://www.boliden.com/Press/News/2015/ Background-on-the-1998-dam-breach-at-the-Los-Frailes-minein-Spain/ (accessed 26/10/2016).

Bolton MD (1986) Strength and dilatancy of sands. Géotechnique 36(1): 65-78, http://dx.doi.org/10.1680/geot.1986.36.1.65.

Bolton MD, Gui MW, Garnier J et al. (1999) Centrifuge cone penetration tests in sand. Géotechnique 49(4): 543-552, http://dx.doi.org/10.1680/geot.1999.49.4.543.

Carter JP, Booker JR and Yeung SK (1986) Cavity expansion in cohesive frictional soils. Géotechnique 36(3): 349-358, http://dx.doi.org/10.1680/geot.1986.36.3.349.

Collins IF, Pender MJ and Yan W (1992) Cavity expansion in sands under drained loading conditions. International Journal for Numerical and Analytical Methods in Geomechanics 16(1): 3-23.

Damavandi-Monfared S and Sadrekarimi A (2015) Development of a miniature cone penetrometer for calibration chamber testing. Geotechnical Testing Journal 38(6): 878-892.
FTDRP (Fundão Tailings Dam Review Panel) (2016) http://www. fundaoinvestigation.com/ (accessed 26/10/2016).

Ghafghazi M and Shuttle DA (2008) Interpretation of sand state from cone penetration resistance. Géotechnique 58(8): 623-634, http://dx.doi.org/10.1680/geot.2008.58.8.623.

Gibson RE (1950) Correspondence. Journal of the Institution of Civil Engineers 34(Supplement 8): 382-383.

Griffiths DV (1980) Finite Element Analysis of Walls, Footings and Slopes. PhD thesis, University of Manchester, Manchester, UK.

ISO (2012) ISO 22476-1: Geotechnical investigation and testing field testing - part 1: Electrical cone and piezocone penetration test. International Organization of Standardization, Geneva, Switzerland.

Jefferies MG (1993) Nor-Sand: a simple critical state model for sand. Géotechnique 43(1): 91-103, http://dx.doi.org/10.1680/ geot.1993.43.1.91.

Jefferies MG (1997) Plastic work and isotropic softening in unloading. Géotechnique 47(5): 1037-1042, http://dx.doi.org/ 10.1680/geot.1997.47.5.1037.

Jefferies MG and Been K (2000) Implications for critical state theory from isotropic compression of sand. Géotechnique 50(4): 419-429, http://dx.doi.org/10.1680/geot.2000.50.4.419.

Jefferies M and Been K (2015) Soil liquefaction: a Critical State Approach, 2nd edn. CRC Press, Boca Raton, FL, USA.

Jefferies MG and Shuttle DA (2002) Dilatancy in general Cambridge-type models. Géotechnique 52(9): 625-638, http://dx.doi.org/10.1680/geot.2002.52.9.625.

Jefferies MG and Shuttle DA (2005) NorSand: features, calibration and use. In Soil Constitutive Models: Evaluation, Selection, and Calibration (Yamamuro JA and Kaliakin VN (eds)). American Society of Civil Engineers, Reston, VA, USA, Geotechnical Special Publication no. 128, pp. 204-236.

Jefferies MG and Shuttle DA (2011) On the operating critical friction ratio in general stress states. Géotechnique 61(8): 709-713, http://dx.doi.org/10.1680/geot.9.T.032.

Ladanyi B and Roy M (1987) Point resistance of piles in sand. Proceedings of the 9th Southeast Asian Geotechnical Conference, Bangkok, Thailand, pp. 6-29.

Lopes R, Bahia R, Jefferies M and Oliveira M (2013) Paste deposition over an existing subaqueous slurry deposit of high sulphide content tailings - the Neves Corvo experience. In Proceedings of Paste 2013, Australian Centre for Geomechanics (Jewell R, Fourie A and Pimenta J (eds)). Australian Centre for Geomechanics, Perth, Australia, pp. 21-36.

Lopes R, Bahia R, Jefferies M and Oliveira M (2015) Upstream stacking of thickened tailings at Neves Corvo. In Paste 2015 Proceedings of the 18th International Seminar on Paste and Thickened Tailings (Jewell R and Fourie A (eds)). Australian Centre for Geomechanics, Perth, Australia, pp. 521-534.

Mohajeri M and Ghafghazi M (2012) Ground sampling and laboratory testing on low plasticity clays. Proceedings of 15 th World Conference on Earthquake Engineering, Lisbon, Portugal.

Mount Polley Independent Expert Engineering Investigation and Review Panel (2016) http://www.mountpolleyreviewpanel.ca/ (accessed 26/10/2016). 
Nova R (1982) A constitutive model for soil under monotonic and cyclic loading. In Soil Mechanics - Transient and Cyclic Loads (Pande GN and Zienkiewicz OC (eds)). Wiley, Chichester, UK, pp. 343-373.

Plewes HD, Davies MP and Jefferies MG (1992) CPT based screening procedure for evaluating liquefaction susceptibility. Proceedings of the 45th Canadian Geotechnical Conference, Toronto, Canada, pp. 1-9.

Peuchen J, Vanden Berghe JF and Coulais C (2010) Estimation of $\mathrm{u} 1 / \mathrm{u} 2$ conversion factor for piezocone. In CPT'10, 2nd International Symposium on Cone Penetration Testing (Robertson PK and Mayne PW (eds)). Omnipress, Madison, WI, USA, Paper 1-03.

Randolph MF, Dolwin J and Beck R (1994) Design of driven piles in sand. Géotechnique 44: 427-448, http://dx.doi.org/10.1680/ geot.1994.44.3.427.

Reid D (2014) Estimating slope of critical state line from cone penetration test - an update. Canadian Geotechnical Journal 52(1): 46-57.

Reynolds O (1885) On the dilatancy of media composed of rigid particles in contact, with experimental illustrations.

Philosophical Magazine 20: 469-481.

Robertson PK and Campanella RG (1983) Interpretation of cone penetration tests - part I: sand. Canadian Geotechnical Journal 20(4): 718-733.

Rowe PW (1962) The stress dilatancy relation for static equilibrium of an assembly of particles in contact. Proceedings of the Royal Society of London A 269(1339): 500-527.

Schofield A and Wroth CP (1968) Critical State Soil Mechanics. McGraw-Hill, London, UK.

Smith IM and Griffiths DV (1988) Programming the Finite Element Method, 2nd edn. Wiley, Hoboken, NJ, USA.

Shuttle DA and Cunning J (2007) Liquefaction potential of silts from CPTu. Canadian Geotechnical Journal 44(1): 1-19.

Shuttle DA and Cunning J (2008) Reply to discussion: Liquefaction potential of silts from CPTu. Canadian Geotechnical Journal 45(1): 142-145.

Shuttle DA and Jefferies MG (1998) Dimensionless and unbiased CPT interpretation in sand. International Journal for Numerical and Analytical Methods in Geomechanics 22(5): 351-391.

Taylor ML, Cubrinovski M and Haycock I (2012) Application of new 'Gel push' sampling procedure to obtain high quality laboratory test data for advanced geotechnical analyses. 2012 New Zealand Society for Earthquake Engineering Conference, Christchurch, New Zealand, Paper 123.

Teh Cl and Houlsby GT (1991) An analytical study of the cone penetration test in clay. Géotechnique 41(1): 17-34, http://dx. doi.org/10.1680/geot.1991.41.1.17.

van den Berg P (1994) Analysis of Soil Penetration. Delft University Press, Delft, the Netherlands.

Wikipedia (2016a) http://wikipedia.org/wiki/Aberfan_disaster (accessed 26/10/2016).

Wikipedia (2016b) http://wikipedia.org/wiki/Mount_Polley_ mine_disaster (accessed 26/10/2016).

Wikipedia (2016c) http://wikipedia.org/wiki/Bento_Rodrigues_ dam_disaster (accessed 26/10/2016).

Willson SM, Ims BW and Smith IM (1989) Finite element analysis of cone penetration. In Penetration Testing in the UK. Thomas Telford, London, UK, pp. 157-160.

Wroth CP (1984) The interpretation of in situ soil tests. Géotechnique 34(4): 449-489, http://dx.doi.org/10.1680/geot. 1984.34.4.449.

Youd TL, Idriss IM, Andrus RD et al. (2001) Liquefaction resistance of soils: summary report from the 1996 NCEER and 1998 NCEER/NSF workshops on evaluation of liquefaction resistance of soils. Journal of Geotechnical and Geoenvironmental Engineering ASCE 127(10): 817-833.

Yu HS (1990) Cavity Expansion Theory and Its Application to the Analysis of Pressuremeters. PhD thesis, University of Oxford, Oxford, UK.

Zienkiewicz OC and Cormeau IC (1974) Viscoplasticity, plasticity and creep in elastic solids: a unified numerical approach. International Journal for Numerical Methods in Engineering 8: 821-845.

Zienkiewicz OC and Taylor RL (1991) The Finite Element Method. McGraw-Hill, New York, NY, USA, vol. 2.

\section{HOW CAN YOU CONTRIBUTE?}

To discuss this paper, please submit up to 500 words to the editor at journals@ice.org.uk. Your contribution will be forwarded to the author(s) for a reply and, if considered appropriate by the editorial board, it will be published as a discussion in a future issue of the journal. 